\title{
Identification and codon reading properties of 5-cyanomethyl uridine, a new modified nucleoside found in the anticodon wobble position of mutant haloarchaeal isoleucine tRNAs
}

\author{
DEBABRATA MANDAL, ${ }^{1,6}$ CAROLINE KÖHRER, ${ }^{1,6}$ DAN SU, ${ }^{2}$ I. RAMESH BABU, ${ }^{2}$ CLEMENT T.Y. CHAN, ${ }^{2}$ \\ YUCHEN LIU, ${ }^{3}$ DIETER SÖLL, ${ }^{3}$ PAUL BLUM, ${ }^{4}$ MASAYASU KUWAHARA, ${ }^{5}$ PETER C. DEDON, ${ }^{2}$ and UTTAM \\ L. RAJBHANDARY ${ }^{1,7}$ \\ ${ }^{1}$ Department of Biology, ${ }^{2}$ Department of Biological Engineering, Massachusetts Institute of Technology, Cambridge, Massachusetts 02139, USA \\ ${ }^{3}$ Department of Molecular Biophysics and Biochemistry, Yale University, New Haven, Connecticut 06520, USA \\ ${ }^{4}$ School of Biological Sciences, University of Nebraska-Lincoln, Lincoln, Nebraska 68508, USA \\ ${ }^{5}$ Graduate School of Science and Technology, Gunma University, Kiryu, Gunma 376-8515, Japan
}

\begin{abstract}
Most archaea and bacteria use a modified $C$ in the anticodon wobble position of isoleucine tRNA to base pair with A but not with $G$ of the mRNA. This allows the tRNA to read the isoleucine codon AUA without also reading the methionine codon AUG. To understand why a modified $C$, and not $U$ or modified $U$, is used to base pair with $A$, we mutated the $C 34$ in the anticodon of Haloarcula marismortui isoleucine tRNA (tRNA ${ }_{2}^{\text {Ile }}$ ) to $\mathrm{U}$, expressed the mutant tRNA in Haloferax volcanii, and purified and

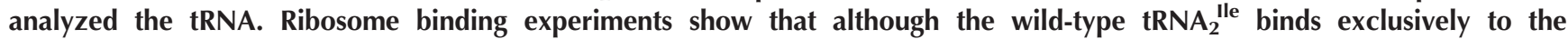
isoleucine codon AUA, the mutant tRNA binds not only to AUA but also to AUU, another isoleucine codon, and to AUG, a methionine codon. The G34 to $U$ mutant in the anticodon of another $\boldsymbol{H}$. marismortui isoleucine tRNA species showed similar codon binding properties. Binding of the mutant tRNA to AUG could lead to misreading of the AUG codon and insertion of isoleucine in place of methionine. This result would explain why most archaea and bacteria do not normally use $U$ or a modified $U$ in the anticodon wobble position of isoleucine tRNA for reading the codon AUA. Biochemical and mass spectrometric analyses of the mutant tRNAs have led to the discovery of a new modified nucleoside, 5-cyanomethyl $U$ in the anticodon wobble position of the mutant tRNAs. 5-Cyanomethyl $U$ is present in total tRNAs from euryarchaea but not in crenarchaea, eubacteria, or eukaryotes.
\end{abstract}

Keywords: 5-cyanomethyl uridine; tRNA modification; anticodon wobble position; codon reading properties; archaea

\section{INTRODUCTION}

Of the 16 four-codon boxes in the genetic code, the AUN box $(\mathrm{N}=\mathrm{U}, \mathrm{C}, \mathrm{A}$, or $\mathrm{G})$ is unique in that three of the four codons AUU, AUC, and AUA specify one amino acid (isoleucine), whereas the fourth codon, AUG, specifies another amino acid (methionine). This three-to-one distribution of codons within a four-codon box is different from essentially all other codon boxes in which all four codons either specify the same amino acid or are split two to two, codons ending in pyrimidines specifying one amino acid, and codons ending in purines specifying a different amino acid (Khorana 1968; Nirenberg 1968).

${ }^{6}$ These authors contributed equally to this work.

${ }^{7}$ Corresponding author

E-mail bhandary@mit.edu

Article published online ahead of print. Article and publication date are at http://www.rnajournal.org/cgi/doi/10.1261/rna.042358.113.
Archaea and bacteria use two different isoleucine tRNAs $\left(\mathrm{tRNA}_{1}{ }^{\text {Ile }}\right.$ and $\left.\mathrm{tRNA}_{2}{ }^{\text {Ile }}\right)$ to read the three isoleucine codons. tRNA $_{1}^{\text {Ile }}$ with the anticodon GAU reads AUU and AUC following the Wobble Hypothesis (Crick 1966), whereas $\mathrm{tRNA}_{2}^{\text {Ile }}$ reads the remaining isoleucine codon AUA without misreading the methionine codon AUG (Harada and Nishimura 1974; Köhrer et al. 2008; Ikeuchi et al. 2010; Mandal et al. 2010). Most interestingly, in both kingdoms, $\mathrm{tRNA}_{2}^{\text {Ile }}$ has almost always $\mathrm{C}^{*} \mathrm{AU}$ as the anticodon sequence, $\mathrm{C}^{*}$, a modified $\mathrm{C}$ in the anticodon wobble position, being agmatidine in archaea (Ikeuchi et al. 2010; Mandal et al.

(C) 2014 Mandal et al. This article is distributed exclusively by the RNA Society for the first 12 months after the full-issue publication date (see http://rnajournal.cshlp.org/site/misc/terms.xhtml). After 12 months, it is available under a Creative Commons License (Attribution-NonCommercial 3.0 Unported), as described at http://creativecommons.org/licenses/by-nc/ $3.0 \%$ 
2010) and lysidine in bacteria (Muramatsu et al. 1988; Grosjean and Björk 2004). Thus, $C^{*}$ can form a base pair with $\underline{A}$ of the AUA but not with $\underline{G}$ of the AUG codon. This raises the question of why archaea and bacteria have evolved a mechanism to use a modified $\mathrm{C}$ instead of a $\mathrm{U}$ or a modified $\mathrm{U}$ to base pair exclusively with $\mathrm{A}$.

In an attempt to answer the preceding question, we mutated the $\mathrm{C}$ in the anticodon of the Haloarcula marismortui $\mathrm{tRNA}_{2}^{\text {Ile }}$ gene to $\mathrm{U}$ (U34 mutant), expressed the mutant tRNA in Haloferax volcanii, and purified it. The mutant tRNA was found to be a poorer substrate for the haloarchaeal isoleucyl-tRNA synthetase (IleRS) in vivo and in vitro. The mutant tRNA was, however, a substrate for Escherichia coli IleRS, and this allowed us to aminoacylate it with isoleucine and study its codon reading properties using $H$. marismortui ribosomes. In contrast to wild-type Ile-tRNA 2 Ile, which binds only to the AUA codon, the U34 mutant tRNA binds not only to AUA but also to AUU, another isoleucine codon, and AUG, a methionine codon. To determine whether the U34 mutant derived from $H$. marismortui $\mathrm{tRNA}_{1}^{\text {Ile }}$ species would have similar coding properties, we also mutated G34 to U34 in the anticodon of $\mathrm{tRNA}_{1}{ }_{1}^{\text {Ile }}$. The $\mathrm{U} 34$ mutant of $\mathrm{tRNA}_{1}{ }^{\text {Ile }}$ also bound to AUA, AUU, and AUG.

Analyses of the U34 mutant tRNAs showed that U34 in the anticodon wobble position is modified to 5-cyanomethyl $\mathrm{U}$ $\left(\mathrm{cnm}^{5} \mathrm{U}\right)$, a new modified nucleoside. We, therefore, investigated (1) whether some other naturally occurring tRNAs in $H$. volcanii contain this modified nucleoside; and (2) how widespread the occurrence of this modified nucleoside is in tRNAs from other archaeal organisms and from other kingdoms. Mass spectrometric analyses of nucleosides present in total tRNAs indicate that $\mathrm{cnm}^{5} \mathrm{U}$ is present in total tRNA from haloarchaea and Methanococcus maripaludis but not in total tRNA from Sulfolobus solfactaricus, Saccharomyces cerevisiae, and Escherichia coli, suggesting its possible presence only in tRNAs from euryarchaea.

\section{RESULTS}

\section{Expression of $\boldsymbol{H}$. marismortui wild-} type and mutant isoleucine tRNAs in $H$. volcanii and growth phenotype of transformants

Previously, we described the purification of $H$. marismortui $\mathrm{tRNA}_{2}^{\text {Ile }}$ and showed that it contained agmatidine in the anticodon wobble position and bound to the isoleucine codon AUA but not to the methionine codon AUG (Mandal et al. 2010). In this work, we mutated the $C$ in the anticodon wobble position of the

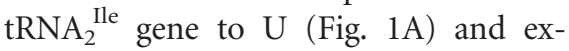

pressed the U34 mutant tRNA in $H$. volcanii. In a parallel experiment, the G34 in the anticodon wobble position of $\mathrm{tRNA}_{1}{ }^{\text {Ile }}$ was also mutated to U34 (Fig. 1B) and expressed in $H$. volcanii.

H. volcanii cells were transformed with pWL201-derived expression vectors carrying either the $H$. marismortui wildtype $\mathrm{tRNA}_{2}{ }^{\text {Ile }}$ gene, mutant $\mathrm{tRNA}_{2}^{\text {Ile }}$ gene, wild-type $\mathrm{tRNA}_{1}^{\text {Ile }}$ gene, or the mutant $\mathrm{tRNA}_{1}^{\text {Ile }}$ gene; the transformants were plated on media containing $4 \mu \mathrm{g} / \mathrm{mL}$ of mevinolin. Colonies of good size appeared 5-7 d after plating; however, transformants containing either of the mutant tRNA genes were always delayed by $\sim 2 \mathrm{~d}$. Also, although plasmids carrying the empty pWL201 vector or either of the wild-type tRNA genes yielded $\sim 10^{7}$ transformants/ $\mu$ g of plasmid DNA, those carrying either of the mutant tRNA genes yielded only $10^{5}-$ $10^{6}$ transformants/ $\mu$ g of plasmid DNA. Additionally, when individual freshly isolated colonies of similar size were used to inoculate liquid media containing mevinolin and growth was monitored over a period of several days, there was a consistent lag of 1-2 d in growth of transformants carrying the mutant tRNA genes (Fig. 1C,D), although the transformants eventually grow at a rate similar those carrying the wild-type tRNA genes. Taken together, these findings suggest that $H$. volcanii cells expressing the mutant $\mathrm{tRNAs}$ are less fit and require a phase of adaptation.

\section{Purification of U34 mutants of $\operatorname{tRNA}_{2}{ }^{\text {Ile }}$ and $\operatorname{tRNA}_{1}{ }^{\text {lle }}$}

As for the wild-type tRNAs, the mutant tRNAs were purified by hybrid selection using a biotinylated DNA oligonucleotide bound to streptavidin-sepharose, followed by native
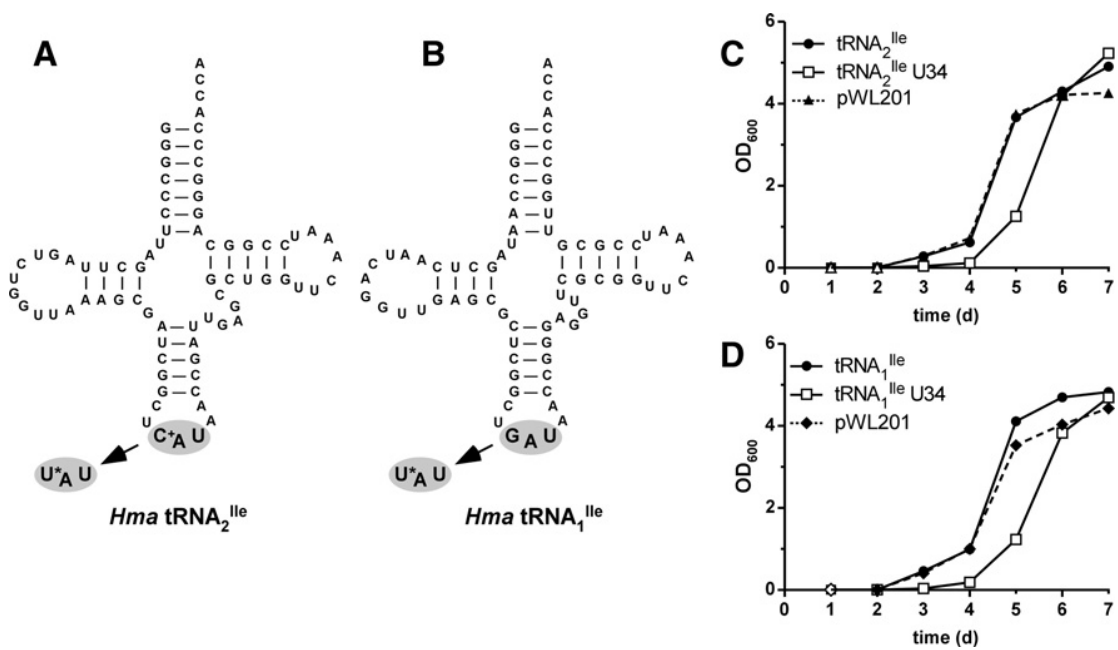

FIGURE 1. H. marismortui isoleucine tRNA mutants containing 5-cyanomethyl uridine at the wobble position. Cloverleaf structures of $\operatorname{tRNA}_{2}^{\text {Ile }}(A)$ and $\mathrm{tRNA}_{1}^{\text {Ile }}(B)$ from H. marismortui. The anticodon changes at the wobble position from $\mathrm{C}^{+}$to $\mathrm{U}^{*}$ and $\mathrm{G}$ to $\mathrm{U}^{*}$, respectively, are indicated. $\left(\mathrm{C}^{+}\right)$agmatidine; ( $\left.\mathrm{U}^{*}\right) 5$-cyanomethyl uridine $\left(\mathrm{cnm}^{5} \mathrm{U}\right)$. Growth of $H$. volcanii cells transformed with plasmids for overexpression of $H$. marismortui $\mathrm{RNA}_{2}^{\text {Ile }}$ wild-type and the $\mathrm{RNA}_{2}^{\text {Ile }}$ $\mathrm{U} 34$ mutant $(C)$, and $H$. marismortui $\mathrm{tRNA}_{1}^{\text {Ile }}$ wild-type and the $\mathrm{RNA}_{1}^{\text {Ile }} \mathrm{U} 34$ mutant $(D)$. The empty vector (pWL201) is shown as a control in $C$ and $D$. 
polyacrylamide gel electrophoresis (Suzuki and Suzuki 2007; Mandal et al. 2010). Figure 2A shows that the purified mutant $\mathrm{tRNA}_{2}^{\text {Ile }}$ is essentially homogeneous and consists of a major band and a minor band (Fig. 2A, left panel, lane 3), both of which hybridize to a DNA oligonucleotide probe complementary to $H$. marismortui $\mathrm{RNA}_{2}^{\text {Ile }}$ (Fig. 2A, right panel, lane 3 ). The yield of purified tRNA from a 12-L culture of $\mathrm{H}$. volcanii was about $4 \mathrm{~A}_{260}$ units and represented $\sim 0.4 \%$ of total tRNA. The U34 mutant of $H$. marismortui $\mathrm{tRNA}_{1}^{\text {Ile }}$ was purified similarly and also yielded a homogeneous product (Supplemental Fig. S1).

Additional evidence for homogeneity of the purified tRNA was derived from partial RNase T1, RNase A, and RNase U2
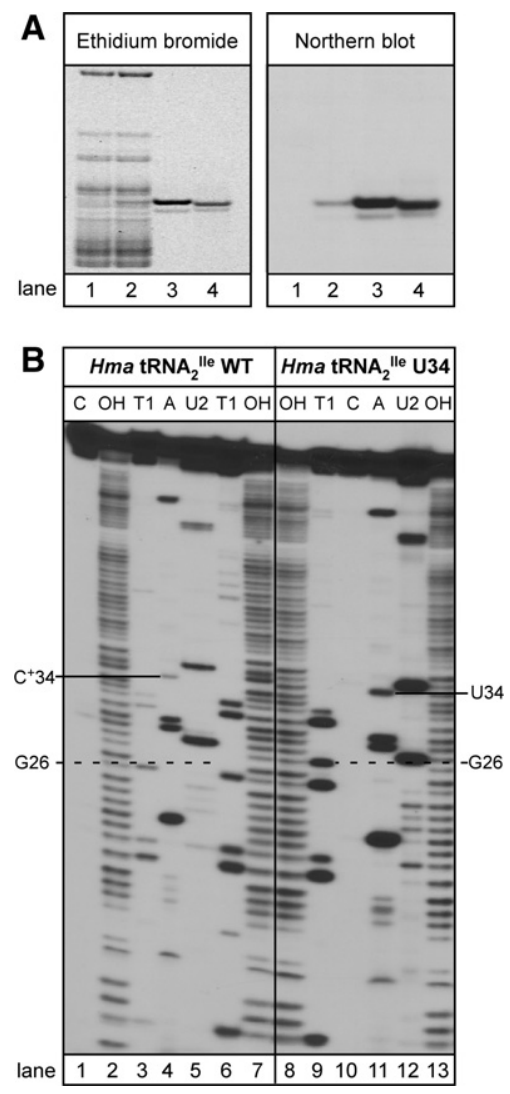

FIGURE 2. Purification and characterization of the $H$. marismortui tRNA $_{2}^{\text {Ile }}$ U34 mutant. (A) Overexpression and purification of the $H$. marismortui RNA $_{2}^{\text {Ile }}$ U34 mutant. Native PAGE analysis of total tRNA from $H$. volcanii (lane 1), total tRNA from $H$. volcanii overexpressing the $H$. marismortui $\mathrm{RRNA}_{2}^{\text {Ile }} \mathrm{U} 34$ mutant (lane 2), and purified $H$. marismortui $\mathrm{tRNA}_{2}^{\text {Ile }} \mathrm{U} 34$ mutant (lane 3). Purified $H$. marismortui wildtype tRNA ${ }_{2}^{\text {Ile }}$ is shown as a control (lane 4 ). One-tenth $\mathrm{A}_{260}$ unit of total tRNA and $0.01 \mathrm{~A}_{260}$ of purified tRNA were applied per lane. tRNAs are visualized by ethidium bromide staining (left panel) or Northern blot analysis using a probe specific for $H$. marismortui RNA $_{2}^{\text {Ile }}$ (right panel). (B) Characterization of purified H. marismortui wild-type and U34 mu-

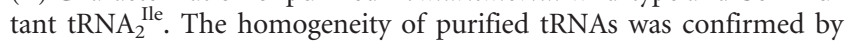
partial RNase T1 (T1 lanes), RNase A (A lanes), RNase U2 (U2 lanes) digests of $5^{\prime}-{ }^{32} \mathrm{P}$-labeled tRNA. Two different concentrations of RNase T1 were used in lanes 3 and 6. (Lane $\mathrm{OH}$ ) partial alkali hydrolysis; (Lane C) undigested tRNA control. ${ }^{32} \mathrm{P}$-labeled fragments were separated by denaturing PAGE and visualized by autoradiography. digests of $5^{\prime}-{ }^{32} \mathrm{P}$-labeled tRNA (Donis-Keller et al. 1977; Simoncsits et al. 1977; Lockard et al. 1978). All the ${ }^{32} \mathrm{P}-\mathrm{la}-$ beled bands present in the RNase T1 digest were as expected for the mutant tRNA and were essentially the same as that for the wild-type tRNA (Fig. 2B, cf. lanes 3 and 6 to lane 9). The only exception was an RNase T1 cut at position 26 of the mutant tRNA, which is absent in RNase T1 digests of the wild-type tRNA. This is most likely due to a partial lack of modification of $\mathrm{G}$ to $\mathrm{N}^{2} \mathrm{~N}^{2}$-dimethyl $\mathrm{G}$ at position 26 in the mutant tRNA. The cleavage patterns seen in digests with RNase A and RNase U2 are also essentially identical between the mutant and the wild-type tRNAs and are, as expected, based on the tRNA sequence (Fig. 2B, cf. lane 4 to lane 11, lane 5 to lane 12). Because partial digestions with RNases A and U2 were carried out in the absence of urea, digestion with these enzymes is more limited compared to digestion with RNase $\mathrm{T} 1$ in the presence of $7 \mathrm{M}$ urea. Basically, similar results were obtained for RNase T1 and RNase A digests of $5^{\prime}-{ }^{32} \mathrm{P}$-labeled wild-type and U34 mutant of $\mathrm{RRNA}_{1}^{\text {Ile }}$ (Supplemental Fig. S2).

\section{The U34 mutant tRNA ${ }_{2}^{\text {Ile }}$ and $\mathrm{tRNA} \mathrm{A}_{1}$ lle overexpressed in $\mathrm{H}$. volcanii are poor substrates for aminoacylation by $H$. volcanii IleRS}

To determine the aminoacylation status of the H. marismortui mutant tRNAs, which are overexpressed in $H$. volcanii, we isolated total tRNA from a small scale culture of $H$. volcanii under acidic conditions, separated tRNAs from aminoacyltRNAs on an acid urea polyacrylamide gel, and detected wild-type and mutant $H$. marismortui $\mathrm{RNA}_{2}^{\text {Ile }}$ by RNA blot hybridization (Varshney et al. 1991; Köhrer and RajBhandary 2008). Both the mutant and the wild-type $\mathrm{RNA}_{2}^{\text {Ile }}$ were aminoacylated rather poorly $(20 \%-25 \%$ and $25 \%-30 \%$, respectively), based on phosphorimager analysis of the bands, in H. volcanii (Fig. 3A, top panel). For the U34 mutant derived from $\mathrm{tRNA}_{1}^{\text {Ile }}$, the corresponding numbers were $\sim 60 \%$ for the mutant and $>90 \%$ for the wild-type tRNA (Fig. 3B, top panel). Control experiments using $H$. volcanii $\mathrm{RRNA}_{2}^{\text {Ile }}$ and tRNA ${ }_{1}^{\text {Ile }}$ probes on the same blots show that the endogenous wild-type $H$. volcanii RNA $_{2}^{\text {Ile }}$ and $\mathrm{tRNA}_{1}^{\text {Ile }}$ are aminoacylated essentially quantitatively (Fig. 3A,B, bottom panels).

In vitro aminoacylation of the purified $H$. marismortui mutant $\mathrm{tRNA}_{2}^{\text {Ile }}$ and $\mathrm{tRNA}_{1}^{\text {Ile }}$ using IleRS present in S10, S30, or S100 extracts of $H$. volcanii showed that the mutant tRNAs were poor substrates for the archaeal IleRS (data not shown). The mutant tRNAs could, however, be aminoacylated essentially quantitatively with ${ }^{3} \mathrm{H}$-Ile using an excess of purified E. coli IleRS (Supplemental Fig. S3).

\section{Codon-reading properties of the U34 mutant $\mathrm{TRNA}_{2}^{\text {Ile }}$ and $\mathrm{TRNA}_{1}^{\text {Ile }}$}

Purified wild-type and mutant $\mathrm{tRNA}_{2}^{\text {Ile }}$ and mutant $\mathrm{tRNA}{ }_{1}^{\text {Ile }}$ were aminoacylated with ${ }^{3} \mathrm{H}$-Ile using E. coli IleRS, and the 

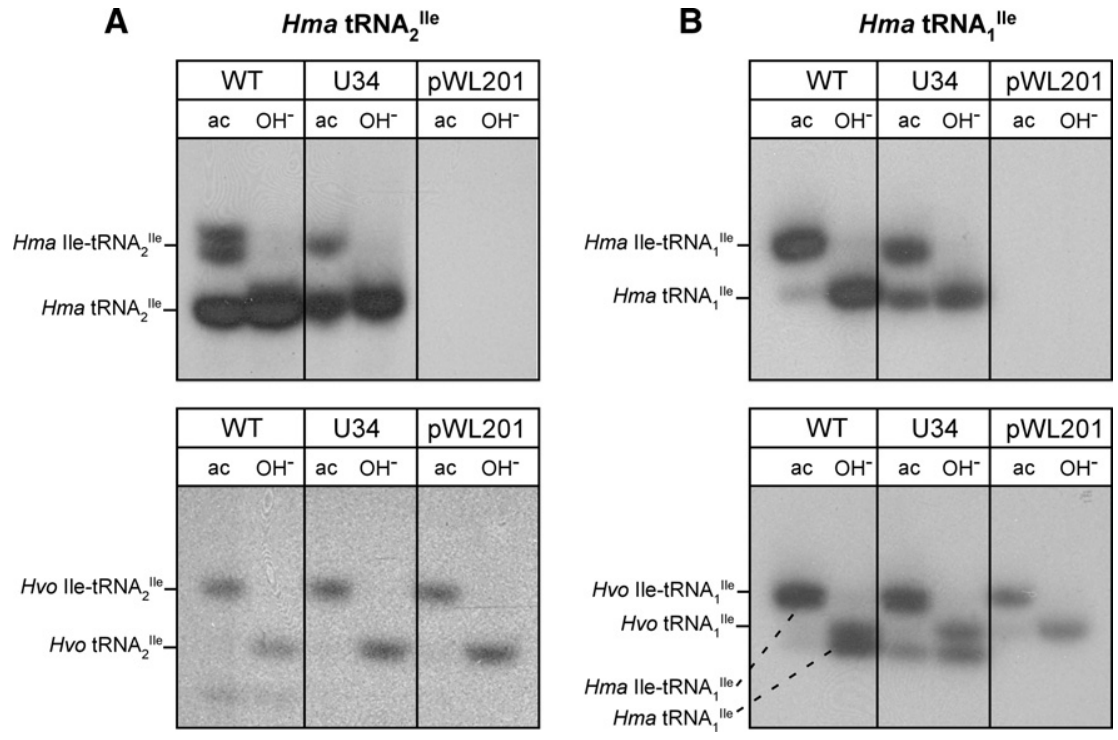

FIGURE 3. State of in vivo aminoacylation of $H$. marismortui wild-type and U34 mutant tRNA 2 Ile $(A)$ and wild-type and U34 mutant H. marismortui $\operatorname{tRNA}_{1}^{\text {Ile }}(B)$. Total tRNA was isolated under acidic conditions and analyzed by acid urea PAGE followed by Northern hybridization using probes specific for $H$. marismortui $\operatorname{tRNA}_{2}^{\text {Ile }}\left(A\right.$, top panel) and $H$. marismortui $\operatorname{tRNA}_{1}^{\text {Ile }}(B$, top panel), respectively. The same blots were stripped and rehybridized using probes specific for the endogenous $H$. volcanii $\mathrm{RNAA}_{2}^{\text {Ile }}\left(A\right.$, bottom panel) and $H$. volcanii $\mathrm{RNA}_{1}^{\text {Ile }}$ ( $B$, bottom panel). Note that the $H$. volcanii $\mathrm{tRNA}_{1}^{\text {Ile }}$-specific probe also picks up the overexpressed $H$. marismortui $\mathrm{tRNA}_{1}^{\text {Ile }}$ because of the high levels of overexpression of $H$. marismortui tRNAs and close sequence similarity between the overexpressed and the endogenous tRNA $A_{1}^{\text {Ile }}$. (ac) tRNA isolated under acidic conditions; $\left(\mathrm{OH}^{-}\right)$tRNA after deacylation by base-treatment.

${ }^{3} \mathrm{H}$-Ile-tRNAs were used for studying oligonucleotide-dependent binding to H. marismortui ribosomes. The oligonucleotides used were AUGAUA, AUGAUC, AUGAUU, and AUGAUG. Figure 4 shows the results. As previously published (Mandal et al. 2010), the wild-type Ile-tRNA ${ }_{2}^{\text {Ile }}$ binds to AUA but not to AUU, AUC, or AUG (Fig. 4A). In contrast, the mutant $\mathrm{tRNA}_{2}^{\text {Ile }}$ binds best to AUA, but it also binds to AUU, another isoleucine codon, and to AUG, a methionine codon (AUA>AUG>AUU) (Fig. 4B). The codon-dependent binding of the tRNA to the ribosome is dependent in all cases on concentration of the oligonucleotide. The codon binding properties of mutant $\mathrm{RRNA}_{1}^{\text {Ile }}$ are the same as those of the mutant tRNA 2 (Ile (AUA $>$ AUG $>$ AUU) (Fig. 4C).

\section{Analysis of nucleotide in the anticodon wobble position of the mutant tRNA}

In view of the codon binding properties of the U34 mutant tRNAs, a key question of interest is whether U34 in the mutant tRNA is modified in H. volcanii; if so, what is the nature of the modification? For this, we partially digested the mutant $\mathrm{tRNA}_{2}^{\mathrm{Ile}}$ randomly with alkali, labeled the $5^{\prime}$-hydroxyl groups of the fragments generated with ${ }^{32} \mathrm{P}$ using $\mathrm{T} 4$ polynucleotide kinase, and separated the $5^{\prime}-{ }^{32} \mathrm{P}$-labeled fragments on a denaturing polyacrylamide gel (Stanley and Vassilenko 1978; Gupta and Randerath 1979; Kuchino et al. 1979; RajBhandary 1980). Figure 5A shows part of the pattern obtained for the wild-type and the mutant tRNAs. The digest of wild-type tRNA shows a pronounced shift in the electrophoretic mobility of fragments, which are produced by cleavage of phosphodiester bonds between nucleotides 33/34 and 34/35, and which differ by one nucleotide. This is due to the presence of the positively charged agmatidine at position 34 (Mandal et al. 2010). As expected, such a shift in mobility between neighboring fragments is not observed in digests of the U34 mutant tRNA.

For identification of the $5^{\prime}$-terminal nucleotides of the fragments, the ${ }^{32} \mathrm{P}-\mathrm{la}-$ beled bands corresponding to nucleotides 32-38 in the anticodon loop of the wild-type and mutant tRNA were eluted from the gel, cleaved with nuclease P1, and the ${ }^{32} \mathrm{P}$-labeled $5^{\prime}$-terminal nucleotide of each fragment was identified by thin layer chromatography (Nishimura 1979; Silberklang et al. 1979). Figure 5B shows the two-dimensional thin layer chromatography pattern obtained for U34 in the mutant tRNA. The $5^{\prime}{ }^{32} \mathrm{P}-\mathrm{la}-$ beled nucleotide migrates very close to, but not identical with, pU. Thus, U34 in the mutant tRNA contains a base modification. A similar analysis of the U34 mutant derived from H. marismortui $\mathrm{tRNA}_{1}^{\text {Ile }}$ shows that U34 in this mutant tRNA also carries the same base modification (Fig. 5C).

\section{Mass spectrometric identification of the modified $\mathrm{U}$ as 5-cyanomethyl $\mathrm{U}\left(\mathrm{cnm}^{5} \mathrm{U}\right)$}

To identify nucleosides that differed between wild-type and the U34 mutant $H$. marismortui $\mathrm{tRNA}_{2}^{\text {Ile }}$, purified $\mathrm{tRNA}_{2}^{\text {Ile }}$ was enzymatically hydrolyzed, and the nucleosides were resolved by reversed-phase HPLC. Comparison of HPLC profiles showed the presence of a nucleoside present exclusively in the mutant $\mathrm{RNA}_{2}^{\text {Ile }}$ (retention time $7.9 \mathrm{~min}$ ) (Fig. 6, vertical arrow). Subsequent analysis of both samples by liquid chromatography-coupled quadrupole time-of-flight mass spectrometry (LC-QTOF) revealed a species with $\mathrm{m} / \mathrm{z}$ 284.0872 (Fig. 7A), again only in the mutant tRNA. In the same high-resolution spectrum, we also identified an ion with $\mathrm{m} / z$ 152.0451, which is consistent with the loss of ribose from a precursor species with $m / z 284.0872$ (Fig. 7A). Similar analysis of a chemically synthesized 5-cyanomethyl-2'-deoxyuridine standard (Fig. 8B; Sakata et al. 1980; Kuwahara et al. 2006) revealed an ion with an identical $\mathrm{m} / \mathrm{z}$ of 152.0451 (Fig. 7C).

The mass spectral data for the modified ribonucleoside identified in this study suggested a chemical formula of 

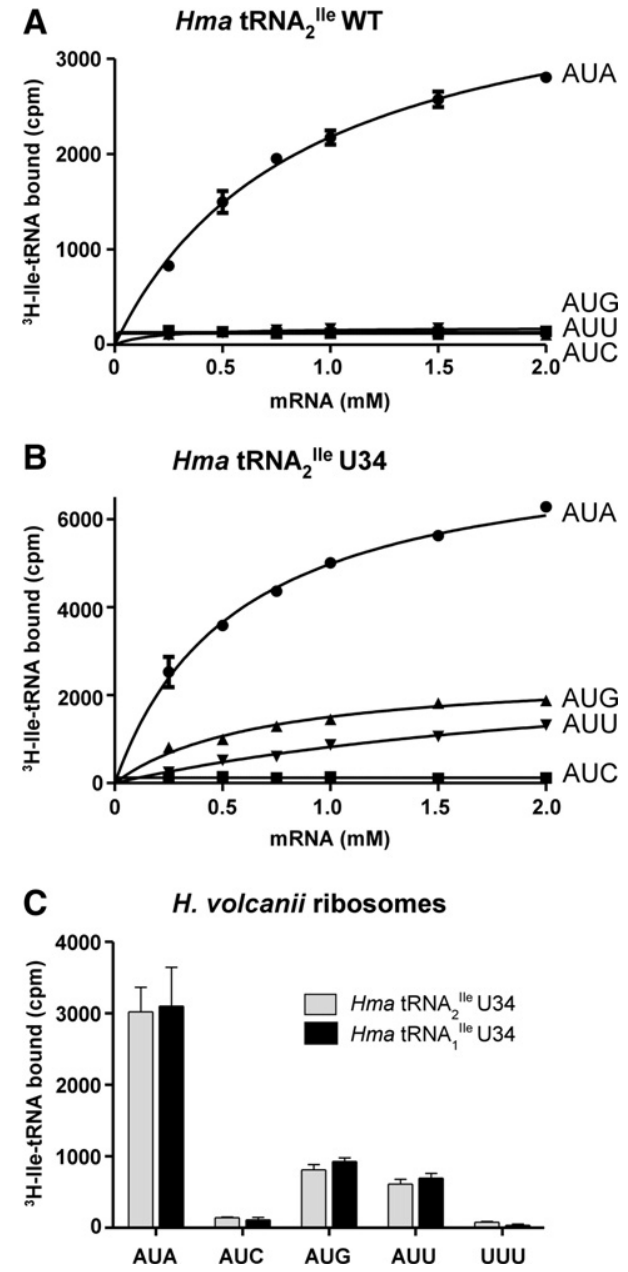

FIGURE 4. Ribosome binding of U34 mutants of $H$. marismortui $\mathrm{tRNA}_{2}^{\text {Ile }}$ and $\mathrm{tRNA}_{1}^{\text {Ile }}$. Template-dependent binding of purified ${ }^{3} \mathrm{H}-$ Ile-tRNA ${ }_{2}^{\text {Ile }}$ wild-type $(A)$ and ${ }^{3} \mathrm{H}$-Ile-tRNA ${ }_{2}^{\text {Ile }} \mathrm{U} 34(B)$ to ribosomes isolated from $H$. marismortui. Oligonucleotides used were AUGAUA, AUGAUC, AUGAUG, and AUGAUU. (C) Binding of purified ${ }^{3} \mathrm{H}$-IletRNA $_{2}^{\text {Ile }}$ U34 and ${ }^{3} \mathrm{H}$-Ile-tRNA 1 Ile $\mathrm{U} 34$ to ribosomes isolated from $H$. volcanii; the mRNA concentration was $1 \mathrm{mM}$; the AUGUUU and "no mRNA" controls are also shown in $C$. Results from three independent experiments are shown.

$\mathrm{C}_{11} \mathrm{H}_{13} \mathrm{~N}_{3} \mathrm{O}_{6}$ (calculated $m / z$ 284.0877), consistent with a $\mathrm{U}$ modified with methylene and cyano functional groups. Comparison of the UV absorption spectra of the modified $\mathrm{U}$ (isolated by HPLC), thymidine, and the synthetic 5-cyanomethyl-2'-deoxyuridine showed that they all had a $\lambda_{\max }$ at $267 \mathrm{~nm}$ (Supplemental Fig. S4), suggesting that the cyano group is not attached directly to the ring, and the modified $\mathrm{U}$ most likely has a $-\mathrm{CH}_{2}-\mathrm{C} \equiv \mathrm{N}$ side chain. Since most tRNA anticodon wobble modifications on $U$ occur at the 5-position of the base (Yokoyama and Nishimura 1995), one candidate structure for the modified $U$ is 5-cyanomethyl uridine $\left(\mathrm{cnm}^{5} \mathrm{U}\right)$ (Fig. 8A).

This structure was confirmed by tandem mass spectrometric analysis of the modified $U$ in comparison with the synthetic 5-cyanomethyl-2'-deoxyuridine. As shown in Figure
$7 \mathrm{~B}$ and $\mathrm{D}$, both the modified $\mathrm{U}$ and 5-cyanomethyl-2'-deoxyuridine were subjected to pseudo- $\mathrm{MS}^{3}$ fragmentation analysis by LC-QTOF. In this analysis, the nucleoside is deglycosylated in-source, and the resulting protonated base was selected by Q1 for further fragmentation by collision induced dissociation (CID) in the collision cell. In the high-resolution tandem mass spectra thus obtained, nucleobases from both the modified U (Fig. 7B) and the synthetic 5-cyanomethyl-2'-deoxyuridine (Fig. 7D) generated identical fragmentation patterns with $m / z$ values of 125,82 , and 54 , which are consistent with the proposed fragmentation pathway shown in Figure 7E. If the cyanomethyl group was present at position 5 of $\mathrm{U}$, and not position 6 , then CID fragmentation should also produce the allene species $5(\mathrm{~m} / z$ 39) shown in Figure 7E. Although this species was not apparent by QTOF analysis due to low sensitivity, analysis of the protonated base ion by in-source fragmentation of the modified $\mathrm{U}$ and the 5-cyanomethyl-2'-deoxyuridine standard by tandem triple-quadruple (QqQ) mass spectrometry revealed a species with $\mathrm{m} / z 39$ for both nucleosides (Fig. 7B,D, insets). Altogether, our data identify $\mathrm{cnm}^{5} \mathrm{U}$ as the unique modified $\mathrm{U}$ in the mutant $H$. marismortui $\mathrm{tRNA}_{2}^{\text {Ile }}$. A similar mass spectrometric analysis of purified mutant $H$. marismortui $\mathrm{tRNA}_{1}$ Ile also confirmed the presence of $\mathrm{cnm}^{5} \mathrm{U}$ in this tRNA (data not shown).

\section{$\mathrm{cnm}^{5} \mathrm{U}$ is present in total tRNAs from haloarchaea and $M$. maripaludis but not in tRNAs from S. solfataricus, S. cerevisiae, and E. coli}

The identification of $\mathrm{cnm}^{5} \mathrm{U}$ as a new modified nucleoside in mutant $H$. marismortui $\mathrm{tRNA}_{2}^{\text {Ile }}$ and $\mathrm{tRNA}_{1}^{\text {Ile }}$ expressed in $H$. volcanii raised the question of whether it is present in total tRNA from $H$. volcanii and from other organisms. To identify $\mathrm{cnm}^{5} \mathrm{U}$ in endogenous tRNAs in $H$. volcanii, we analyzed total tRNA digests with or without expression of the H. marismortui $\mathrm{U} 34$ mutant $\mathrm{tRNA}_{2}^{\text {Ile }}$ by QTOF. To reduce background and improve detection, ribonucleosides in total tRNA digests were separated by HPLC, and fractions eluting in the region of $\mathrm{cnm}^{5} \mathrm{U}$ were collected and subjected to LC-QTOF. We found $\mathrm{cnm}^{5} \mathrm{U}$ in total tRNA with or without expression of the U34 mutant $H$. marismortui $\mathrm{RNA}_{2}{ }^{\text {Ile }}$, suggesting the presence of $\mathrm{cnm}^{5} \mathrm{U}$ in endogenous tRNAs in $H$. volcanii (data not shown). We also developed a multiple reaction-monitoring (MRM) method based on the fragmentation information from the LC-QTOF analysis of 5-cyanomethyl-2'-deoxyuridine and $\mathrm{cnm}^{5} \mathrm{U}$, using a tandem triple-quadrupole mass spectrometer (Fig. 9A); and using this approach, we observe a distinct peak corresponding to $\mathrm{cnm}^{5} \mathrm{U}$ in total tRNA isolated from wild-type $H$. volcanii cells (Fig. 9B).

We subsequently analyzed total tRNA from Halobacterium salinarum, H. marismortui, M. maripaludis, S. solfataricus, $S$. cerevisiae, and E. coli for the presence of $\mathrm{cnm}^{5} \mathrm{U}$. In the case of $H$. salinarum, $H$. marismortui, $M$. maripaludis, and S. solfataricus, total tRNA digests were directly analyzed using the 


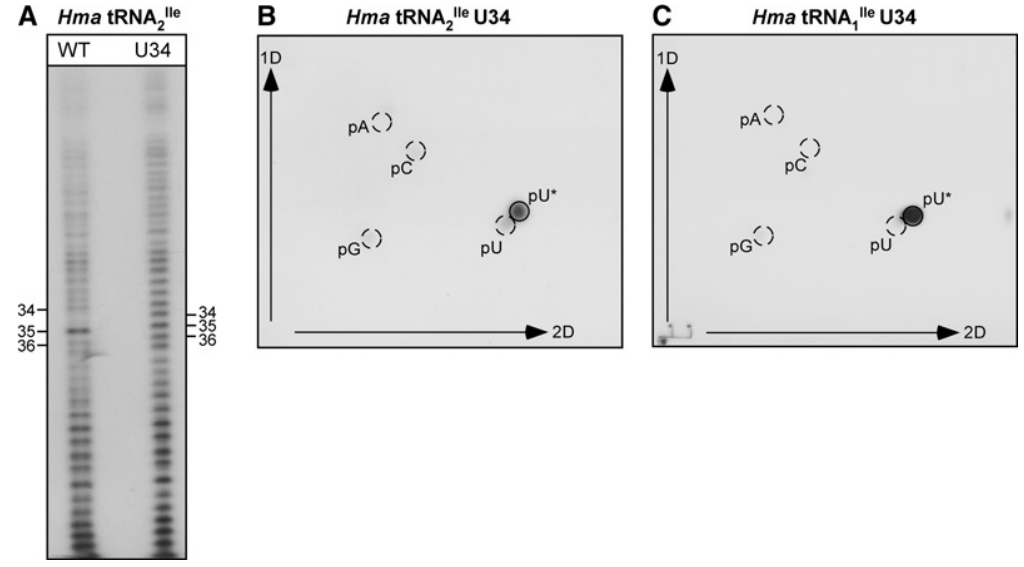

FIGURE 5. $5^{\prime}-{ }^{32} \mathrm{P}$-labeling of random alkali fragments $(A)$, and $2 \mathrm{D}$-TLC analysis of the wobble base nucleotide in U34 mutants of $H$. marismortui $\operatorname{tRNA}_{2}^{\text {Ile }}(B)$ and $\operatorname{tRNA}_{1}^{\text {Ile }}(C)$. Purified tRNAs were cleaved randomly with alkali; fragments were $5^{\prime}$-end labeled with ${ }^{32} \mathrm{P}$ and separated by gel electrophoresis. The $5^{\prime}$-end nucleotide of the fragment corresponding to $U^{*} 34$ was analyzed by nuclease $\mathrm{P} 1$ digestion and 2D-TLC. Nonradioactive markers pA, $\mathrm{pC}, \mathrm{pG}$, and $\mathrm{pU}$ were visualized by UV-shadowing and are indicated by circles. $\left(\mathrm{pU}^{*}\right)$ position of $\mathrm{cnm}^{5} \mathrm{U}$.

AUG also occurs in vivo. This would explain why nearly all archaea and bacteria use a modified $\mathrm{C}$ and not $\mathrm{U}$ or a modified $\mathrm{U}$ in the anticodon wobble position to read the isoleucine codon AUA. Although agmatidine and lysidine, both modified derivatives of $C$, base pair specifically with A of AUA, similar derivatives of $\mathrm{U}$ have so far not been found in nature. It is likely that such $\mathrm{U}$ derivatives would have tautomeric structures in which both the $\mathrm{N}^{3}$ and $\mathrm{O}^{4}$ could act as $\mathrm{H}$-bond acceptors and, therefore, be incapable of forming stable base pairs with A on the ribosome.

Our results do not, however, rule out the possibility that some archaeal or bacterial organism will use $\mathrm{U}$ or a different modified $U$ in the anticodon wobble position to read the isoleucine codon AUA without also reading the methionine codon AUG. For example, most eukaryotic

MRM method (Fig. 9C-F); in the case of S. cerevisiae and E. coli, HPLC fractions eluting at the $\mathrm{cnm}^{5} \mathrm{U}$ retention time were collected and the prepurified fractions were subjected to LCQTOF analysis (Fig. 9G,H). In all cases, purified $\mathrm{cnm}^{5} \mathrm{U}$ from the U34 mutant tRNA ${ }_{2}^{\text {Ile }}$ and total tRNAs from $H$. volcanii were used as positive control. Within the detection limits of the instrument, we found $\mathrm{cnm}^{5} \mathrm{U}$ in total tRNA from haloarchaea and M. maripaludis but not from S. solfactaricus, $S$. cerevisiae, and E. coli.

\section{DISCUSSION}

To answer the question why most bacterial and archaeal isoleucine tRNAs use lysidine or agmatidine in the anticodon wobble position to base pair exclusively with A but not with G, we have reported here the expression, purification, and analysis of the codon binding properties of mutants of $H$. marismortui $\mathrm{RNA}_{2}^{\text {Ile }}$ and $\mathrm{RNAA}_{1}^{\text {Ile }}$, in which the anticodon wobble position has been mutated to $\mathrm{U}$. The U34 mutants of $H$. marismortui $\mathrm{RNA}_{2}^{\text {Ile }}$ and $\mathrm{tRNA}_{1}^{\text {Ile }}$ bind not only to the isoleucine codons AUA and AUU but also to the methionine codon AUG. Binding to AUG could lead to misreading of AUG and insertion of isoleucine in place of methionine into proteins. The extent of misreading of the AUG codon in $H$. volcanii would, however, depend upon several factors, including the extent of aminoacylation of the mutant tRNA, its concentration in vivo, its relative affinity for the AUG codon on the ribosome, and competition by the endogenous $H$. volcanii elongator Met-tRNA ${ }^{\text {Met }}$, which normally binds to the AUG codon. The findings that transformants carrying the genes for the U34 mutants of $\mathrm{RNA}_{2}^{\text {Ile }}$ or $\mathrm{tRNA}_{1}^{\text {Ile }}$ have a growth disadvantage compared with those carrying the wild-type $\mathrm{tRNA}_{2}^{\text {Ile }}$ or tRNA 1 (lle (Fig. 1C,D) suggest that misreading of organisms encode an isoleucine tRNA ( $\mathrm{RNA}_{2}^{\text {Ile }}$ ) that has a U modified to $\Psi$ in the anticodon wobble position (Senger et al. 1997). The $\Psi$ in this tRNA is thought to base pair with A of the AUA codon but not with G of the AUG codon. Also, it is known that two archaeal organisms, a nanoarchaeon and a korachaeon (Waters et al. 2003; Randau et al. 2005; Elkins et al. 2008), and some bacteria including Mycoplasma mobile, Bifidobacterium adolescentis, and a mutant strain of B. subtilis encode tRNA ${ }^{\text {Ile }}$ with a UAU in the anticodon (Fabret et al. 2011). It has been shown that the $U$ in the anticodon wobble position of tRNA ${ }^{\text {Ile }}$ from $M$. mobile and the mutant tRNA ${ }^{\text {Ile }}$ from $B$. subtilis is not modified, and these tRNAs read the isoleucine codon AUA without misreading the methionine

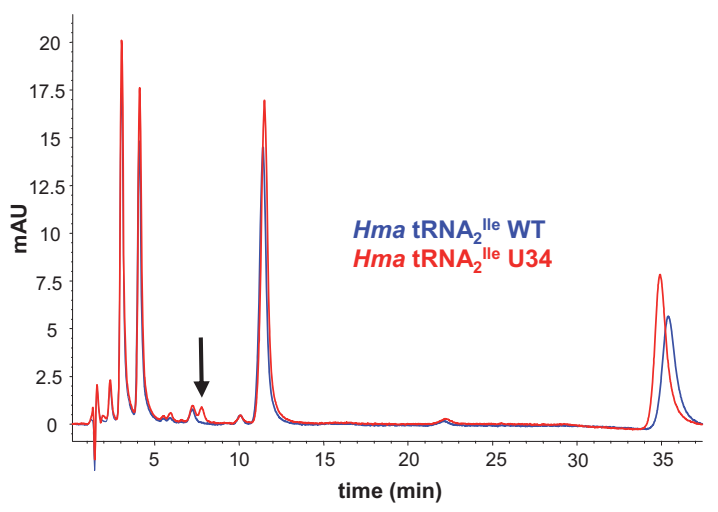

FIGURE 6. Identification of a unique ribonucleoside species in the U34 mutant tRNA ${ }_{2}^{\text {Ile }}$. Purified $H$. marismortui wild-type and the U34 mutant thereof were digested to ribonucleosides and resolved by HPLC. The UV $(260 \mathrm{~nm})$ absorption patterns of the two digests were overlaid, and a unique peak was identified in the mutant sample, highlighted by the arrow. 
$A$

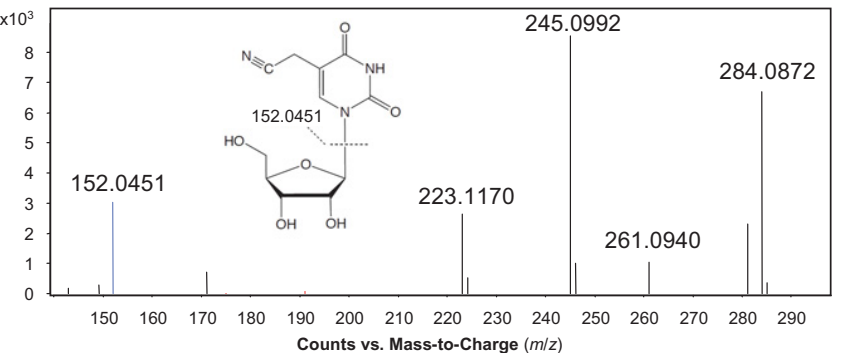

B

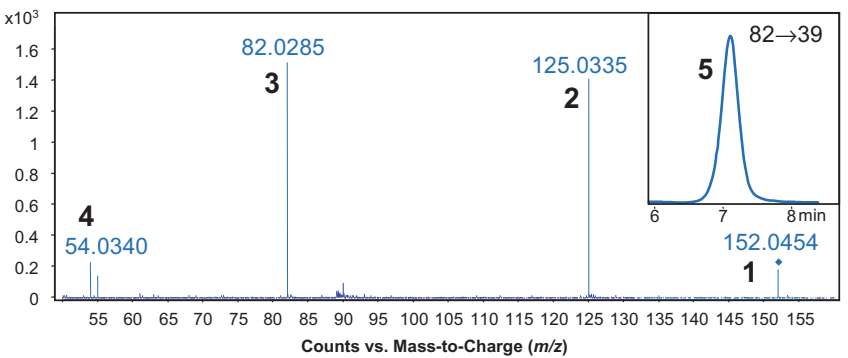

C
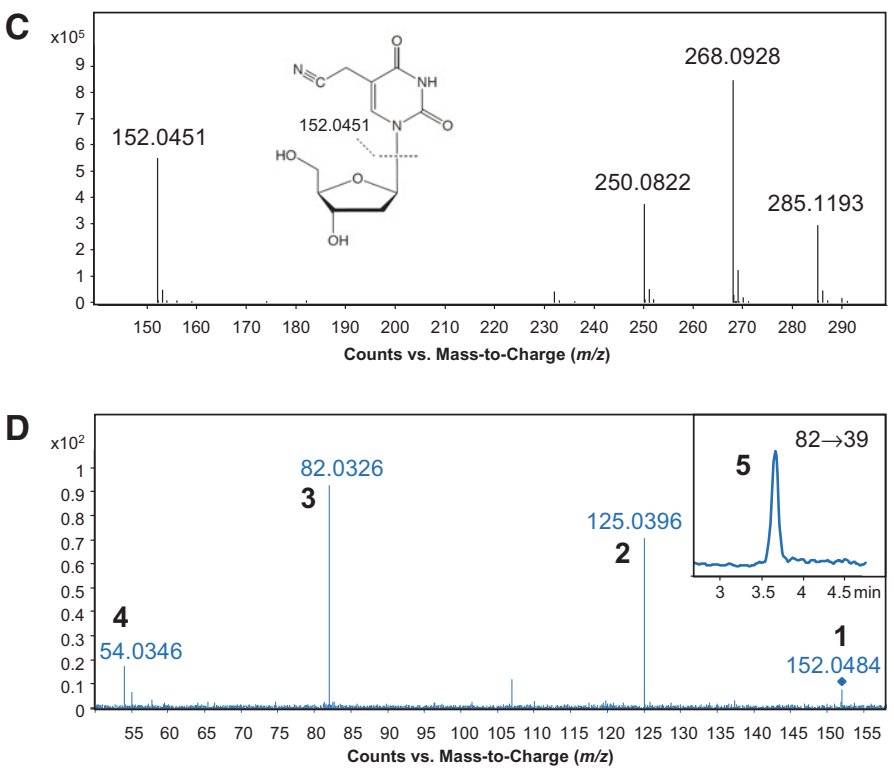

E

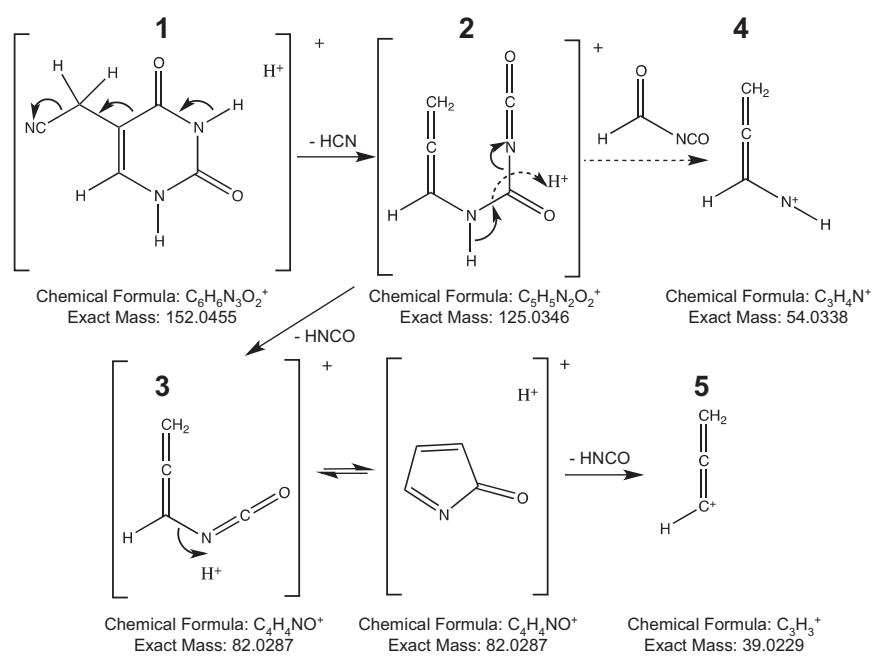

FIGURE 7. (Legend on next page) codon AUG to any significant extent in vivo and in vitro (Köhrer et al. 2013; Taniguchi et al. 2013). It is possible that in these few organisms, the ribosomes and the tRNA ${ }^{\text {Ile }}$ sequences have coevolved in such a way that $U$ or a modified $U$ base pairs much better with $A$ than with G.

Characterization of the U34 mutants of $H$. marismortui $\mathrm{tRNA}_{2}^{\text {Ile }}$ and $\mathrm{tRNA}_{1}^{\text {Ile }}$ led to the discovery of $\mathrm{cnm}^{5} \mathrm{U}$, a new modified nucleoside in $H$. volcanii. Mass spectrometric analysis of nucleosides derived from total tRNAs isolated from $H$. volcanii, $H$. salinarum, $H$. marismortui, and $M$. maripaludis has shown that this modified nucleoside is also present in endogenous tRNAs from these organisms but not in total tRNAs isolated from S. solfactaricus (a crenarchaeon), S. cerevisiae, or E. coli. Thus, $\mathrm{cnm}^{5} \mathrm{U}$ may be present mostly in tRNAs from euryarchaea.

Ribosome binding experiments with the U34 mutant of $H$. marismortui tRNA $_{2}^{\text {Ile }}$ show that it binds to AUA, AUU, and AUG (AUA $>A U G>A U U)$ with minimal binding, if any, to AUC (Fig. 4B,C). The corresponding mutant of tRNA ${ }_{1}^{\text {Ile }}$ also binds to AUA, AUU, and AUG but not to AUC (Fig. 4C). These results suggest that $\mathrm{cnm}^{5} \mathrm{U}$ in the anticodon wobble position of a tRNA forms base pairs with $U, A$, or $G$ on the mRNA.

The codons of a four-codon box in the genetic code Table are, in general, read by at least two tRNAs. For example, in eukaryotes a tRNA with inosine in the anticodon wobble position reads codons ending in $U, C$, and $A$, whereas another tRNA with $\mathrm{C}$ in the anticodon wobble position reads codons ending in $G$ (Björk 1998). In contrast, in bacteria such as E. coli, a tRNA with $5^{\prime}$-carboxymethoxy $\mathrm{U}\left(\mathrm{cmo}^{5} \mathrm{U}\right)$ in the anticodon wobble position reads codons ending in $\mathrm{U}, \mathrm{A}$, and $\mathrm{G}$, whereas another tRNA with $\mathrm{G}$ in the anticodon wobble position reads codons ending in $\mathrm{U}$ and $\mathrm{C}$ (Murao et al. 1970; Yokoyama and Nishimura 1995). Similarly, in B. subtilis, a tRNA with $5^{\prime}$-methoxy $\mathrm{U}\left(\mathrm{mo}^{5} \mathrm{U}\right)$ reads codons ending in $\mathrm{U}, \mathrm{A}$, and $\mathrm{G}$, and a tRNA with $\mathrm{G}$ in the anticodon reads codons ending in U and C (Murao et al. 1976; Yokoyama 
and Nishimura 1995). Information on the codon recognition patterns and properties of archaeal tRNAs is, however, quite limited. Except for the classical work of Gupta on nucleotide sequences of $H$. volcanii tRNAs and identification of many of the modified bases in these tRNAs (Gupta 1984, 1986) and identification of genes encoding many of the tRNA modifying enzymes using bioinformatic analyses (Phillips and de Crecy-Lagard 2011), there has been very little work done with purified tRNAs from archaea and on the codon recognition properties of archaeal tRNAs. The results we have obtained with two mutant haloarchaeal tRNAs containing $\mathrm{cnm}^{5} \mathrm{U}$ in the anticodon wobble position suggest that the codon recognition properties of $\mathrm{cnm}^{5} \mathrm{U}$, which base pairs with $\mathrm{U}$, A, or G, parallel those of $\mathrm{cmo}^{5} \mathrm{U}$ in E. coli and $\mathrm{mo}^{5} \mathrm{U}$ in $B$. subtilis. With the knowledge that other tRNAs in $H$. volcanii contain $\mathrm{cnm}^{5} \mathrm{U}$ (this work), it becomes important now to purify and identify these tRNAs and establish their codon recognition properties using $H$. volcanii ribosomes.

Finally, in spite of the fact that $H$. volcanii tRNAs have been among the best studied among the archaea in terms of nucleotide sequences and base modifications, our recent work on two haloarchaeal tRNAs, $\mathrm{tRNA}_{2}^{\text {Ile }}$ and a mutant derived from it, led to the discovery of two new modified nucleosides, agmatidine and 5-cyanomethyl uridine in $H$. volcanii and other haloarchaea. With so many other archaeal organisms, whose tRNAs have not been purified or studied to any extent, most likely there are many modified nucleosides with interesting structures and functions that remain to be discovered (Phillips and de Crecy-Lagard 2011). The methods for tRNA purification and analysis used here combined with the increased power and sophistication of mass spectral techniques and instrumentation should significantly facilitate this discovery.

\section{MATERIALS AND METHODS}

\section{General}

Strain H. volcanii WFD11 and plasmids pUCsptProM and pWL201 (Lam and Doolittle 1989; Nieuwlandt and Daniels 1990) were kindly provided by Drs. John R. Palmer and Charles J. Daniels (Department of Microbiology, Ohio State University). H. marismortui ATCC 43,049 was kindly provided by Dr. Peter Moore (Department of Chemistry, Yale University). The E. coli strains used in this work,

FIGURE 7. Structural elucidation of 5-cyanomethyl uridine. $(A, C)$ High mass-accuracy mass spectra of the unknown ribonucleoside species $(A)$ found in the purified $H$. marismortui tRNA $_{2}^{\text {Ile }}$ U34 mutant and the 5-cyanomethyl-2'-deoxyuridine synthetic standard $(C)$. The parent ions have $\mathrm{m} / \mathrm{z}$ values of $284.0872(A)$ and $268.0928(C)$, and the deglycosylated base ions have identical $\mathrm{m} / \mathrm{z}$ values of $152.0451(A, C)$. (B,D) Pseudo-MS ${ }^{3}$ mass spectra of the unknown ribonucleoside species $(B)$ and the 5-cyanomethyl-2'-deoxyuridine synthetic standard $(D)$. Following in-source fragmentation of the parent ribonucleoside, the deglycosylated base ion was subjected to CID, with the product ions (numbered 1-5) in close agreement with the theoretical fragmentation pathway shown in panel $E$. The MRM chromatogram of the $m / z 82 \rightarrow 39$ transition (species 5 ) is shown in the insets of $B$ and $D$. (E) Proposed fragmentation pathway for 5-cyanomethyl uracil, with each numbered fragment along with its formula and exact mass.
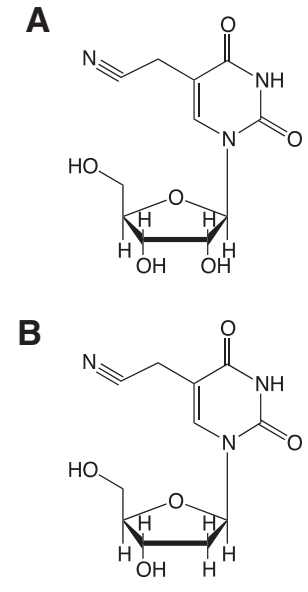

FIGURE 8. Chemical structures of 5-cyanomethyl uridine $(A)$ and 5cyanomethyl-2'-deoxyuridine $(B)$.

E. coli XL1-blue and E. coli GM2163, have been described before (Ramesh and RajBhandary 2001). General manipulations of H. marismortui, $H$. volcanii, and E. coli were performed according to standard procedures (DasSarma and Fleischmann 1995; Sambrook and Russell 2001). RNase T1, RNase A, RNase U2, nuclease P1, and snake venom phosphodiesterase I were from Sigma; T4 polynucleokinase (T4-PNK), antarctic phosphatase, calf intestinal phosphatase, and inorganic pyrophosphatase were from New England Biolabs; DNA and RNA oligonucleotides were from IDT; and oligonucleotides used for cloning, detection, and purification of tRNAs are listed in Supplemental Table S1.

\section{Cloning and overexpression of $\boldsymbol{H}$. marismortui $\mathrm{RRNA}_{2}^{\text {lle }}$ and RNNA $_{1}^{\text {lle }}$ (WT and the U34 mutant)}

The gene for $H$. marismortui $\mathrm{tRNA}_{2}^{\text {Ile }}$ was first cloned into the vector pUCsptProM (Ramesh and RajBhandary 2001). For this, the gene for H. marismortui tRNA ${ }_{2}^{\text {Ile }}$ was PCR amplified from $H$. marismortui genomic DNA and inserted into the XbaI and BamHI sites of plasmid pUCsptProM downstream from the tRNA ${ }^{\text {Lys }}$ promoter to generate pUCHmalle2WT. The C34 to U34 mutation in the anticodon of $\mathrm{tRNA}_{2}^{\text {Ile }}$ was generated by QuikChange mutagenesis (Stratagene) using pUCHmalle2WT as template. A HindIII/EcoRI fragment containing the wild-type tRNA ${ }_{2}^{\text {Ile }}$ gene or its U34 mutant, including the tRNA ${ }^{\text {Lys }}$ promoter, was subcloned into the shuttle plasmid pWL201 to generate pWLHmaIle2WT and pWLHmaIle2MUT. Similarly, pWLHmaIle1WT and pWLHmaIle1MUT carrying the $H$. marismortui wild-type tRNA Ile gene or its U34 mutant were generated. All initial cloning was done in E. coli XL-1 blue. After confirming the sequences of the desired wild-type and mutant tRNA genes, the respective plasmids were used to transform E. coli GM2163 $\left(\mathrm{dam}^{-}\right)$. Plasmid DNA isolated from this strain was then used to transform $H$. volcanii as described (DasSarma and Fleischmann 1995; Ramesh and RajBhandary 2001). Transformants were grown in $H$. volcanii medium containing $4 \mu \mathrm{g} / \mathrm{mL}$ mevinolin (US Biologicals). 

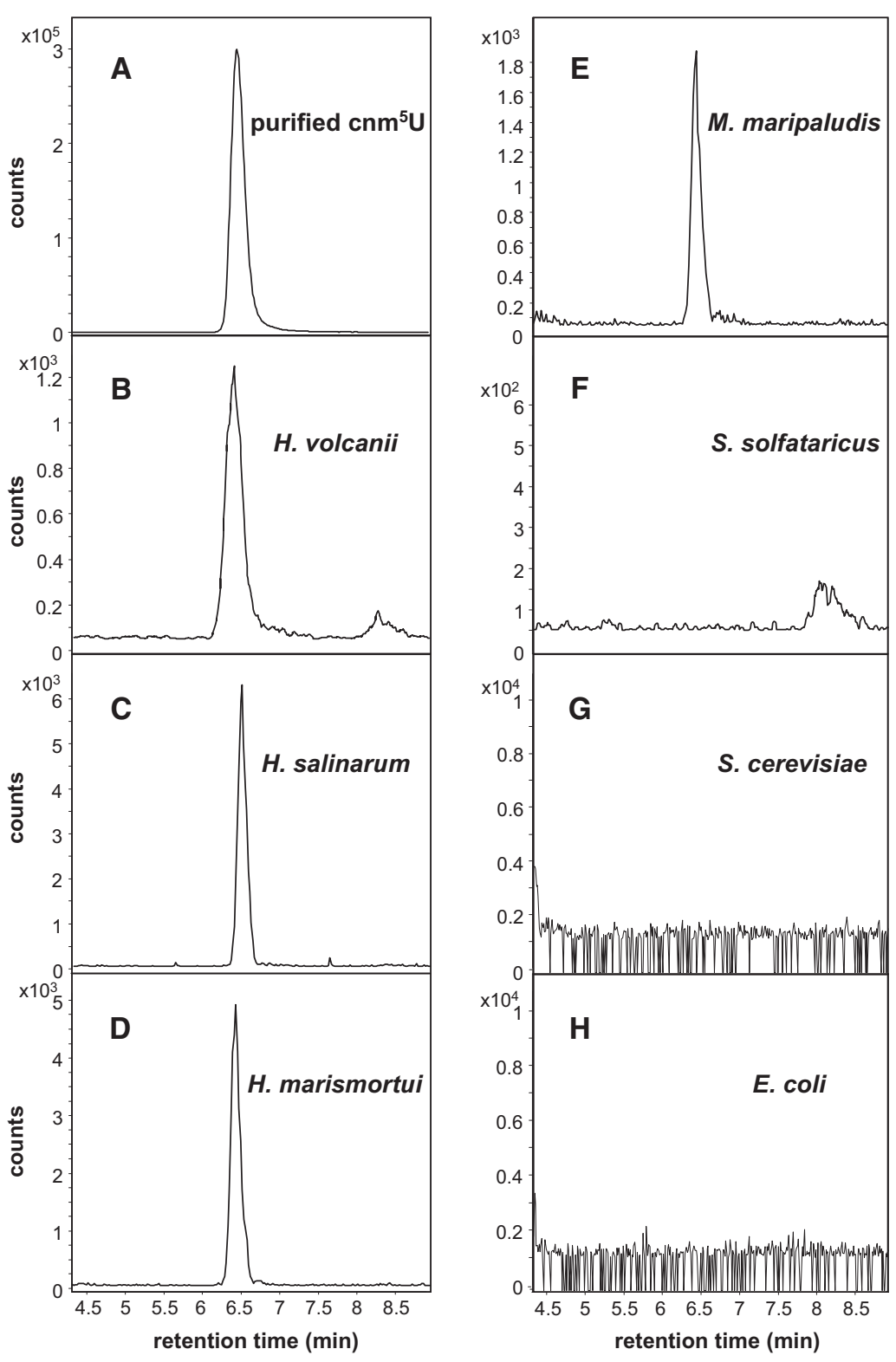

FIGURE 9. $\mathrm{cnm}^{5} \mathrm{U}$ in total tRNAs from haloarchaea, M. maripaludis, S. solfataricus, S. cerevisiae, and E. coli. Nucleoside detection was performed, either by monitoring $m / z 284.2 \rightarrow 125$ transition on an Agilent 6510 triple-quadrupole mass spectrometer $(A-F)$ or by extracted ion chromatogram for the nucleoside $\mathrm{m} / \mathrm{z} 284.2$ on an Agilent 6520 QTOF mass spectrometer $(G, H)$.

\section{Polyacrylamide gel electrophoresis (PAGE) and Northern blot analysis of tRNA}

Total RNA was extracted under acidic conditions using Trizol (Invitrogen) as described before (Köhrer et al. 2008). RNA was resuspended in $10 \mathrm{mM}$ sodium acetate $\mathrm{pH} 5.0$ and stored at $-80^{\circ} \mathrm{C}$. tRNAs were analyzed by acid urea PAGE (Varshney et al. 1991; Köhrer and RajBhandary 2008) or native PAGE as indicated, followed by Northern blotting (Köhrer and RajBhandary 2008). tRNAs were visualized by hybridization using ${ }^{32} \mathrm{P}$-labeled DNA oligonucleotides according to standard procedures (Sambrook and Russell 2001). Oligonucleotides were 5 '-end labeled with $\gamma$ - $\left[{ }^{32} \mathrm{P}\right]$-ATP (3000 Ci/mmol; PerkinElmer) using T4-PNK. North- ern blots were analyzed by autoradiography followed by PhosphorImaging using Imagequant software.

\section{Purification of overexpressed $H$. marismortui tRNA $\mathrm{A}_{2}^{\text {Ile }}$ and $\mathrm{TRNA}_{1}$ "le (WT and U34 mutant) from $H$. volcanii}

H. volcanii transformants were grown at $37^{\circ} \mathrm{C}$ to an $\mathrm{OD}_{600}$ of $3-3.5$, and crude RNA was isolated by acid guanidinium thiocyanatephenol-chloroform extraction (Chomczynski and Sacchi 2006). Ribosomal RNA was removed by precipitation with $1 \mathrm{M} \mathrm{LiCl}$ yielding total tRNA. Purification of overexpressed isoleucine tRNAs was done as described earlier for tRNA 2 Ile (Suzuki and Suzuki 2007; Mandal et al. 2010), involving hybrid selection of the desired tRNA using a biotinylated DNA oligonucleotides immobilized to a streptavidin resin. The biotinylated oligonucleotide for $\mathrm{tRNA}_{2}^{\text {Ile }}$ purification was complementary to nucleotides 54-73 of the tRNA; the biotinylated oligonucleotide for $\mathrm{RRNA}_{1}^{\text {Ile }}$ purification was complementary to nucleotides 39-58 of the tRNA. Affinity purification was followed by electrophoresis of the enriched tRNA on native $10 \%-12.5 \%$ polyacrylamide gels. After elution from the gel and extensive dialysis against $5 \mathrm{mM}$ ammonium acetate $\mathrm{pH}$ 5.5, the tRNA was concentrated by evaporation, precipitated with ethanol, and the precipitate was washed several times with $70 \%$ ethanol. Typically, about $4.0 \mathrm{~A}_{260}$ units of the U34 mutant of $\mathrm{RNA}_{2}^{\text {Ile }}$ were obtained from approximately $1000 \mathrm{~A}_{260}$ of total tRNA; about 5.5 $\mathrm{A}_{260}$ units of the $\mathrm{U} 34$ mutant of $\mathrm{tRNA}_{1}^{\text {Ile }}$ were obtained from about $400 \mathrm{~A}_{260}$ of total tRNA. The purity of the tRNAs was assessed by PAGE, in vitro aminoacylation with isoleucine, and partial digestion of $5^{\prime}-{ }^{32} \mathrm{P}$-labeled tRNAs with RNases T1, A, and U2.

\section{In vitro aminoacylation of tRNA}

One hundredth to $1.0 \mathrm{~A}_{260}$ units of tRNA were aminoacylated in vitro with L-isoleucine as described below using purified E. coli IleRS or S10, S30, or S100 extracts prepared from $H$. volcanii. Reaction mixtures using purified E. coli IleRS contained $50 \mathrm{mM}$ 4-(2-hydroxyethyl)piperazine-1-ethanesulfonic acid (Hepes) $\mathrm{pH}$ 7.5, $10 \mathrm{mM}$ $\mathrm{MgCl}_{2}, 5 \mathrm{mM}$ ATP, $0.1 \mu \mathrm{g} / \mu \mathrm{L}$ BSA, $5 \mu \mathrm{M}\left[{ }^{3} \mathrm{H}\right]$-isoleucine (American Radiolabeled Chemicals), and $0.05 \mu \mathrm{M}$ of IleRS. Alternatively, in vitro aminoacylations were carried using S10, S30, or S100 extracts from $H$. volcanii in a reaction containing 10 mM Hepes pH 7.5, $2.5 \mathrm{M} \mathrm{KCl,} 50 \mathrm{mM} \mathrm{Mg(OAc)})_{2}, 5 \mathrm{mM}$ ATP, 5 $\mu \mathrm{M}\left[{ }^{3} \mathrm{H}\right]$-isoleucine, and $\sim 0.5 \mu \mathrm{g} / \mu \mathrm{L}$ extract. At various time points, aliquots were removed and analyzed by precipitation with TCA followed by liquid scintillation counting of TCA-precipitable counts. 
Background (obtained from reactions run without tRNA) was subtracted from all values unless otherwise noted. Quantitative aminoacylation of purified $H$. marismortui isoleucine tRNAs for ribosome binding assays were carried out with purified E. coli IleRS; for this, reactions were allowed to proceed for $2 \mathrm{~h}$, and inorganic pyrophosphatase was added at a final concentration of 0.04 units/ $\mu \mathrm{L}$. After aminoacylation, tRNAs were extracted with acid phenol and precipitated with ethanol.

\section{Isolation of $\boldsymbol{H}$. marismortui and $\boldsymbol{H}$. volcanii ribosomes}

Ribosomes from $H$. marismortui and $H$. volcanii were isolated as described (Mandal et al. 2010) using the basic procedure of Wittman and coworkers (Shevack et al. 1985) with minor modifications. Cells from a $2 \mathrm{~L}$ culture grown to midlog phase $\left(\mathrm{OD}_{600} \sim 3.5\right)$ were suspended in ice-cold $10 \mathrm{mM}$ Hepes $\mathrm{pH} 7.5,100 \mathrm{mM} \mathrm{Mg}(\mathrm{OAc})_{2}, 3.4$ $\mathrm{M} \mathrm{KCl}$ and $6 \mathrm{mM}$ 2-mercaptoethanol ("high-salt ribosome buffer"), and lysed by French Press (Constant Cell Disruption System; 10,000 Psi, 2 passages). The ribosomes were then prepared as described, resuspended in "high-salt ribosome buffer," divided into aliquots, quick frozen, and stored at $-80^{\circ} \mathrm{C}$.

\section{Binding of aminoacylated tRNAs to ribosomes}

The mRNA oligonucleotides (AUGAUA, AUGAUC, AUGAUU, AUGAUG, and AUGUUU) used in the ribosome binding experiments were stored at a stock concentration of $10 \mathrm{mM}$. The standard

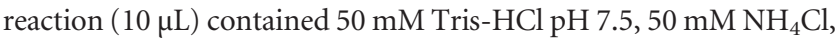
$5 \mathrm{mM} \mathrm{Mg}(\mathrm{OAc})_{2}, 3 \mathrm{mM}$ 2-mercaptoethanol, $2.1 \mathrm{M} \mathrm{KCl}, 1.2 \mathrm{~A}_{260}$ units of $H$. marismortui ribosomes, RNA oligonucleotides $(0-1.5$ $\mathrm{mM})$, and $\sim 1.6$ pmol $\left[{ }^{3} \mathrm{H}\right]$-labeled tRNA $(10,000 \mathrm{cpm})$. Alternatively, reactions $(20 \mu \mathrm{L})$ contained $50 \mathrm{mM}$ Hepes $\mathrm{pH} 7.5$, $50 \mathrm{mM} \mathrm{NH}_{4} \mathrm{Cl}, 50 \mathrm{mM} \mathrm{Mg}(\mathrm{OAc})_{2}, 3 \mathrm{mM}$ 2-mercaptoethanol, 2.1 $\mathrm{M} \mathrm{KCl}, 1 \mathrm{~A}_{260}$ unit of $H$. volcanii ribosomes, RNA oligonucleotides $(0-1.5 \mathrm{mM})$, and $\sim 1.6 \mathrm{pmol}\left[{ }^{3} \mathrm{H}\right]$-labeled tRNA $(10,000 \mathrm{cpm})$. Incubation was at room temperature for $1 \mathrm{~h}$. The reaction was stopped by adding $0.5 \mathrm{~mL}$ wash buffer $[50 \mathrm{mM}$ Tris- $\mathrm{HCl}$ or Hepes pH 7.5, $\left.50 \mathrm{mM} \mathrm{NH}_{4} \mathrm{Cl}, 5 \mathrm{mM} \mathrm{Mg}(\mathrm{OAc})_{2}, 2.1 \mathrm{M} \mathrm{KCl}\right]$, and the mixture was filtered through a nitrocellulose filter (HA 0.45 $\mu \mathrm{m}$, Millipore) prewashed with the same buffer. The filters were washed several times with wash buffer, dried, and counted for radioactivity in a liquid scintillation counter.

\section{$5^{\prime}{ }^{32} \mathrm{P}$-end labeling and partial digestion of tRNA}

tRNA $\left(0.01 \mathrm{~A}_{260}\right)$ was dephosphorylated with 1 unit of calf intestinal phosphatase in a $50-\mu \mathrm{L}$ reaction containing $50 \mathrm{mM}$ Tris- $\mathrm{HCl} \mathrm{pH} 7.9$ and $1 \mathrm{mM}$ EDTA. Before adding enzyme, the mixture was incubated for $2 \mathrm{~min}$ at $65^{\circ} \mathrm{C}$ and then for $5 \mathrm{~min}$ at $37^{\circ} \mathrm{C}$. After dephosphorylation for $30 \mathrm{~min}$ at $37^{\circ} \mathrm{C}$, the reaction mixture was incubated with $5 \mathrm{mM}$ nitrilotriacetic acid (Sigma) for $30 \mathrm{~min}$ at room temperature, and the phosphatase was inactivated by heat for $2 \mathrm{~min}$ at $65^{\circ} \mathrm{C}$. Dephosphorylated tRNAs were labeled with ${ }^{32} \mathrm{P}$ at the $5^{\prime}$ terminus in a $50-\mu \mathrm{L}$ reaction containing $70 \mathrm{mM}$ Tris- $\mathrm{HCl} \mathrm{pH} \mathrm{7.5,} 10 \mathrm{mM}$ $\mathrm{MgCl}_{2}, 5 \mathrm{mM}$ dithiothreitol (DTT), 10 pmol of $\gamma$ - $\left[{ }^{32} \mathrm{P}\right]-\mathrm{ATP}$, and $20 \mathrm{U}$ of T4-PNK. After $30 \mathrm{~min}$ of incubation at $37^{\circ} \mathrm{C}$, the ${ }^{32} \mathrm{P}$-labeled tRNA was precipitated with a 2.5 volume of ethanol, $0.2 \mathrm{M}$ ammonium acetate $\mathrm{pH}$ 5.2, and $10 \mu \mathrm{g}$ glycogen (Ambion). The precipitate was washed with $70 \%$ ethanol. ${ }^{32} \mathrm{P}$-labeled tRNA was separated by electrophoresis on a $6 \%$ denaturing polyacrylamide gel, and the band corresponding to the full-length tRNA was excised and eluted in $10 \mathrm{mM}$ Tris- $\mathrm{HCl} \mathrm{pH} 7.5$ and $5 \mathrm{mM} \mathrm{MgCl}_{2}$. The eluted radiolabeled tRNA was further precipitated and washed as above and then dissolved in sterile water.

For partial alkali hydrolysis and partial RNase digestions, 20,000 cpm of ${ }^{32} \mathrm{P}$-labeled tRNA and $0.01 \mathrm{~A}_{260}$ units of total H. marismortui tRNA were used in reaction volumes of 7.5-10 $\mu \mathrm{L}$. The partial alkali hydrolysis reaction was in $33 \mathrm{mM} \mathrm{Na} \mathrm{CO}_{3} / \mathrm{NaHCO}_{3}$ buffer $\mathrm{pH} 9.2$ for $2-3 \mathrm{~min}$ at $95^{\circ} \mathrm{C}$. The partial RNase T1 digestion was in $50 \mathrm{mM}$ Tris- $\mathrm{HCl} \mathrm{pH}$ 7.5, $7 \mathrm{M}$ urea and 5-10 $\mathrm{U}$ of RNase T1 and incubation was for $10 \mathrm{~min}$ at $50^{\circ} \mathrm{C}$. Partial digestion with RNase U2 (0.002 unit) was in $50 \mathrm{mM}$ ammonium acetate $\mathrm{pH} 4.5$ for $5 \mathrm{~min}$ at $37^{\circ} \mathrm{C}$. Partial digestion with RNase A (0.002-0.005 unit) was in $10 \mathrm{mM}$ Tris- $\mathrm{HCl}$ ( $\mathrm{pH} 8.0$ ), $1 \mathrm{mM}$ EDTA for $5 \mathrm{~min}$ at $37^{\circ} \mathrm{C}$. After the incubation, samples were quick frozen, lyophilized to dryness, and then dissolved in formamide loading buffer. The samples were separated by electrophoresis on a $10 \%$ denaturing polyacrylamide gel; gels were dried and then used for autoradiography.

\section{Nuclease P1 digests of $5^{\prime}{ }^{32} \mathrm{P}$-end labeled fragments of tRNA}

Purified tRNAs $\left(0.01 \mathrm{~A}_{260}\right)$ were partially hydrolyzed with alkali as described above. The mixture was evaporated to dryness, and the residue was dissolved in $10 \mu \mathrm{L}$ water. Digested tRNA $\left(0.001 \mathrm{~A}_{260}\right)$ was incubated with 5 units of T4-PNK in a $20-\mu \mathrm{L}$ reaction containing $70 \mathrm{mM}$ Tris- $\mathrm{HCl} \mathrm{pH} \mathrm{7.5,} 10 \mathrm{mM} \mathrm{MgCl}_{2}, 5 \mathrm{mM}$ DTT, and 2.5 pmol $\gamma$ - $\left[{ }^{32} \mathrm{P}\right]$-ATP for $5 \mathrm{~min}$ at $37^{\circ} \mathrm{C}$. The $5^{\prime}-{ }^{32} \mathrm{P}$-labeled fragments were separated by $10 \%$ denaturing PAGE, and bands corresponding to the anticodon base U34 (for mutant $\mathrm{tRNA}_{2}^{\text {Ile }}$ and $\mathrm{tRNA}_{1}^{\text {Ile }}$ ) and bases preceding and following U34 were eluted with buffer A (20 $\mathrm{mM}$ Tris- $\mathrm{HCl} \mathrm{pH} \mathrm{7.5,} 10 \mathrm{mM} \mathrm{MgCl}_{2}$ ), precipitated with ethanol, washed, dissolved in sterile water, and digested with nuclease P1 in $50 \mathrm{mM}$ ammonium acetate buffer $\mathrm{pH} 5.0$ overnight at $37^{\circ} \mathrm{C}$. The incubation mixtures were quick frozen on dry ice and lyophilized under vacuum. Nucleotides were dissolved in sterile water and lyophilized to dryness three times to remove any ammonium acetate prior to thin layer chromatography.

\section{Thin layer chromatography}

Cellulose F plates $(20 \times 20 \mathrm{~cm})$ with fluorescent background used for two-dimensional thin layer chromatography (2D-TLC) analyses were obtained from Merck. The solvent system for the first and second dimension were as follows: (1) isobutyric acid:concentrated ammonia:water (66:1:33); and (2) isopropanol:concentrated $\mathrm{HCl}$ : water (70:15:15). The first dimension was run in Solvent 1 for $\sim 16 \mathrm{~h}$; the plates were then dried overnight. The second dimension was run in Solvent 2 for $\sim 28 \mathrm{~h}$. Plates were dried and analyzed by autoradiography. Nonradioactive nucleotides were used as markers and visualized by UV shadowing.

\section{Enzymatic hydrolysis of tRNA and HPLC analysis of modified ribonucleosides}

Purified H. marismortui $\mathrm{tRNA}_{2}^{\text {Ile }}$ and $\mathrm{tRNA}_{1}^{\text {Ile }}$ (WT and U34 mutants) and total tRNA from $H$. volcanii, $H$. salinarum, $H$. 
marismortui, M. maripaludis, S. solfataricus, S. cerevisiae, and E. coli were digested to nucleosides using nuclease $\mathrm{P} 1$, snake venom phosphodiesterase I, and antarctic phosphatase as described in detail by Crain (Crain 1990). After digestion, nucleosides were passed through a centrifugal filter (Amicon Ultra; 10K) for removal of enzymes.

Nucleosides were then separated by HPLC using an Agilent 1100 HPLC and a Thermo Scientific Hypersil GOLD aQ reverse-phase column $(150 \times 2.1 \mathrm{~mm}, 3 \mu \mathrm{m})$ eluted with the following gradient of water to acetonitrile containing $8 \mathrm{mM}$ ammonium acetate at a flow rate of $0.3 \mathrm{~mL} / \mathrm{min}$ and $36^{\circ} \mathrm{C}$ : $0-18 \mathrm{~min}, 0 \%$; $18-23 \mathrm{~min}$, $0 \%-1 \%$; 23-28 $\mathrm{min}, 1 \%-6 \%$; 28-30 $\mathrm{min}, 6 \%$; 30-40 $\mathrm{min}, 6 \%-$ $100 \%$; 40-50 min, 100\%; the HPLC eluent was monitored at 260 $\mathrm{nm}$ using a diode-array detector.

\section{Liquid chromatography-coupled mass spectrometric analysis of ribonucleosides}

Ribonucleosides identified by HPLC were structurally characterized by LC-MS analysis. Initial analysis of the unknown ribonucleoside was performed using an Agilent 1290 UPLC equipped with diode array detectors and a Thermo Scientific Hypersil GOLD aQ C18 reverse-phase column $(100 \times 1 \mathrm{~mm}, 1.9 \mu \mathrm{m}$ particle size $)$ that was coupled to an Agilent 6510 QTOF high resolution mass spectrometer with an electrospray ionization source operated in positive ion mode with the following parameters: drying gas temperature, $325^{\circ} \mathrm{C}$; drying gas flow, $8 \mathrm{~L} / \mathrm{min}$; nebulizer, $25 \mathrm{psi}$; and capillary voltage, $3500 \mathrm{~V}$. The QTOF was operated in MS mode, with $140 \mathrm{~V}$ fragmentor voltage and with mass range $\mathrm{m} / \mathrm{z}$ 100-1000. HPLC resolution was performed with the same gradient as before of water to acetonitrile at a flow rate of $70 \mu \mathrm{L} / \mathrm{min}$ and $36^{\circ} \mathrm{C}$ : $0-18 \mathrm{~min}, 0 \%$; $18-23 \mathrm{~min}, 0 \%-1 \%$; 23-28 min, $1 \%-6 \%$; 28-30 min, 6\%; 30-40 min, 6\%-100\%; 40-50 min, 100\%. The unknown species with $\mathrm{m} / \mathrm{z} 284.0872$ eluted at $6.6 \mathrm{~min}$.

Collision induced dissociation (CID) experiments were performed using an Agilent 1200 HPLC with the same Thermo Scientific Hypersil GOLD aQ reverse-phase column coupled to the QTOF mass spectrometer. HPLC resolution was performed isocratically with $8 \mathrm{mM}$ ammonium acetate at a flow rate of $70 \mu \mathrm{L} / \mathrm{min}$ for $20 \mathrm{~min}$ and $36^{\circ} \mathrm{C}$. The unknown species with $\mathrm{m} / \mathrm{z} 284.0872$ eluted at $4.27 \mathrm{~min}$ and 5-cyanomethyl-2'-deoxyuridine eluted at 3.56 min. The initial CID analysis of 5-cyanomethyl-2'-deoxyuridine and the unknown molecular species was performed in targeted MS/MS mode on $\mathrm{m} / \mathrm{z} 268.0928$ or $\mathrm{m} / \mathrm{z} 284.08771$, respectively, and a fragmentor voltage of $140 \mathrm{~V}$ or $90 \mathrm{~V}$, respectively, with collision energies of $5 \mathrm{~V}, 10 \mathrm{~V}$, or $15 \mathrm{~V}$ used to optimize product ion formation. In-source fragmentation and subsequent CID analysis of protonated base was used to perform pseudo-MS ${ }^{3}$ analysis of both 5-cyanomethyl-2'-deoxyuridine and the unknown molecular species. In this analysis, a fragmentor voltage $300 \mathrm{~V}$ was used in targeted MS/MS on the $m / z 152.04545$ fragment of 5-cyanomethyl-2'-deoxyuridine, with collision energies of $5 \mathrm{~V}, 10 \mathrm{~V}$, or $15 \mathrm{~V}$. For the unknown species, a fragmentor voltage of $160 \mathrm{~V}$ was used for targeted MS/MS on the $\mathrm{m} / z 152.04545$ fragment of the unknown ribonucleoside.

Subsequent fragmentation analysis by triple-quadrupole (QqQ) mass spectrometry was performed by MRM analysis using an Agilent 1100 HPLC with a Thermo Scientific Hypersil GOLD aQ column $(150 \times 2.1 \mathrm{~mm}, 3 \mu \mathrm{m}$ particle size $)$ coupled to an Agilent
6410 QqQ mass spectrometer. For analysis of 5-cyanomethyl-2'deoxyuridine and the purified unknown species, ribonucleosides were eluted isocratically with $8 \mathrm{mM}$ ammonium acetate at a flow rate of $0.2 \mathrm{~mL} / \mathrm{min}$ for $20 \mathrm{~min}$ and $36^{\circ} \mathrm{C}$. The QqQ mass spectrometer with an electrospray ionization source was operated in positive ion mode with the following parameters: drying gas temperature, $325^{\circ} \mathrm{C}$; drying gas flow, $8 \mathrm{~L} / \mathrm{min}$; nebulizer, $30 \mathrm{psi}$; and capillary voltage, $4000 \mathrm{~V}$. The first and third quadrupoles (Q1 and Q3) were set to unit resolution and the monitored ion transitions. The $m / z$ of the transmitted parent ion, $\mathrm{m} / \mathrm{z}$ of the monitored product ion, fragmentor voltage, and collision energy, respectively, for 5-cyanomethyl-2'-deoxyuridine were as follows: $268.2 \rightarrow 152.1,90$ $\mathrm{V}, 5 \mathrm{~V} ; 152.1 \rightarrow 125.1,140 \mathrm{~V}, 5 \mathrm{~V} ; 125.1 \rightarrow 82.1,150 \mathrm{~V}, 10 \mathrm{~V}$; $82.1 \rightarrow 39,160 \mathrm{~V}, 15 \mathrm{~V}$. For $\mathrm{cnm}^{5} \mathrm{U}$, the parameters were: $284.2 \rightarrow 152.1,90 \mathrm{~V}, 5 \mathrm{~V} ; 152.1 \rightarrow 125.1,140 \mathrm{~V}, 5 \mathrm{~V} ; 125.1 \rightarrow 82.1$, $150 \mathrm{~V}, 10 \mathrm{~V} ; 82.1 \rightarrow 39,170 \mathrm{~V}, 15 \mathrm{~V}$. All MRM produced peaks at the same retention time (transition $82.1 \rightarrow 39$ shown in Fig. $7 \mathrm{~B}$, inset), suggesting they are from the same parent compound. Detection of $\mathrm{cnm}^{5} \mathrm{U}$ in purified tRNA or total tRNA was achieved by resolving enzymatic hydrolysates on the reversed-phase HPLC column with a gradient of water to acetonitrile containing $8 \mathrm{mM}$ ammonium acetate at a flow rate of $0.2 \mathrm{~mL} / \mathrm{min}$ and $36^{\circ} \mathrm{C}$ : $0-15$ $\min , 0 \%$; 15-16 $\mathrm{min}, 0 \%-100 \%$; 16-20 $\mathrm{min}, 100 \%$; 20-21 $\mathrm{min}$, $100 \%-0 \%$. The QqQ mass spectrometer was operated in positive ion mode with the following parameters: gas temperature, $325^{\circ} \mathrm{C}$; gas flow, $10 \mathrm{~L} / \mathrm{min}$; nebulizer, $20 \mathrm{psi}$; and capillary voltage, 4000 $\mathrm{V}$. The $\mathrm{m} / \mathrm{z}$ of the transmitted parent ion, $\mathrm{m} / \mathrm{z}$ of the monitored product ion, fragmentor voltage, and collision energy were as follows: $284.2 \rightarrow 125.1,110 \mathrm{~V}, 15 \mathrm{~V} ; 152.1 \rightarrow 125.1,140 \mathrm{~V}, 10 \mathrm{~V}$; $152.1 \rightarrow 82.1,140 \mathrm{~V}, 15 \mathrm{~V}$.

\section{SUPPLEMENTAL MATERIAL}

Supplemental material is available for this article.

\section{ACKNOWLEDGMENTS}

We thank Annmarie McInnis for her usual cheerfulness and help with preparing this manuscript. This work was supported by grants from the US National Institutes of Health (GM17151 to U.L.R.; GM22854 to D. Söll; ES017010 to P.C.D.); the Singapore-MIT Alliance for Research and Technology sponsored by the National Research Foundation of Singapore (P.C.D.); and the Department of Energy (DE-FG36-08GO88055 to P.B.).

Received September 6, 2013; accepted October 30, 2013.

\section{REFERENCES}

Björk GR. 1998. Modified nucleosides at positions 34 and 37 of tRNAs and their predicted coding capacities. In Modification and editing of RNA (ed. Grosjean H, Benne R), pp. 577-581. American Society for Microbiology, Washington, DC.

Chomczynski P, Sacchi N. 2006. The single-step method of RNA isolation by acid guanidinium thiocyanate-phenol-chloroform extraction: Twenty-something years on. Nat Protoc 1: 581585.

Crain PF. 1990. Preparation and enzymatic hydrolysis of DNA and RNA for mass spectrometry. Methods Enzymol 193: 782-790. 
Crick FH. 1966. Codon-anticodon pairing: The wobble hypothesis J Mol Biol 19: 548-555.

DasSarma S, Fleischmann EM. 1995. Archaea: A laboratory manualhalophiles. Cold Spring Harbor Laboratory Press, Cold Spring Harbor, NY.

Donis-Keller H, Maxam AM, Gilbert W. 1977. Mapping adenines, guanines, and pyrimidines in RNA. Nucleic Acids Res 4: 25272538.

Elkins JG, Podar M, Graham DE, Makarova KS, Wolf Y, Randau L, Hedlund BP, Brochier-Armanet C, Kunin V, Anderson I, et al. 2008. A korarchaeal genome reveals insights into the evolution of the Archaea. Proc Natl Acad Sci 105: 8102-8107.

Fabret C, Dervyn E, Dalmais B, Guillot A, Marck C, Grosjean H, Noirot P. 2011. Life without the essential bacterial tRNA ${ }^{\text {Ile2 }}$-lysidine synthetase TilS: A case of tRNA gene recruitment in Bacillus subtilis. Mol Microbiol 80: 1062-1074.

Grosjean H, Björk GR. 2004. Enzymatic conversion of cytidine to lysidine in anticodon of bacterial tRNA ${ }^{\text {Ile }}$ — an alternative way of RNA editing. Trends Biochem Sci 29: 165-168.

Gupta R. 1984. Halobacterium volcanii tRNAs. Identification of 41 tRNAs covering all amino acids, and the sequences of 33 class I tRNAs. J Biol Chem 259: 9461-9471.

Gupta R. 1986. Transfer RNAs of Halobacterium volcanii: Sequences of five leucine and three serine transfer RNAs. Syst Appl Microbiol 7: $102-105$.

Gupta RC, Randerath K. 1979. Rapid print-readout technique for sequencing of RNA's containing modified nucleotides. Nucleic Acids Res 6: 3443-3458.

Harada F, Nishimura S. 1974. Purification and characterization of AUA specific isoleucine transfer ribonucleic acid from Escherichia coli B. Biochemistry 13: 300-307.

Ikeuchi Y, Kimura S, Numata T, Nakamura D, Yokogawa T, Ogata T, Wada T, Suzuki T. 2010. Agmatine-conjugated cytidine in a tRNA anticodon is essential for AUA decoding in archaea. Nat Chem Biol 6: 277-282.

Khorana HG. 1968. Nucleic acid synthesis in the study of the genetic code. In Nobel lectures. Elsevier, Amsterdam.

Köhrer C, RajBhandary UL. 2008. The many applications of acid urea polyacrylamide gel electrophoresis to studies of tRNAs and aminoacyl-tRNA synthetases. Methods 44: 129-138.

Köhrer C, Srinivasan G, Mandal D, Mallick B, Ghosh Z, Chakrabarti J, RajBhandary UL. 2008. Identification and characterization of a tRNA decoding the rare AUA codon in Haloarcula marismortui. RNA 14: 117-126.

Köhrer C, Mandal D, Gaston KW, Grosjean H, Limbach PA, RajBhandary UL. 2013. Life without tRNA ${ }^{\text {Ile }}$-lysidine synthetase: Translation of the isoleucine codon AUA in Bacillus subtilis lacking the canonical tRNA ${ }_{2}^{\text {Ile }}$. Nucleic Acids Res doi: 10.1093/nar/gkt1009.

Kuchino Y, Kato M, Sugisaki H, Nishimura S. 1979. Nucleotide sequence of starfish initiator tRNA. Nucleic Acids Res 6: 34593469.

Kuwahara M, Nagashima J, Hasegawa M, Tamura T, Kitagata R, Hanawa K, Hososhima S, Kasamatsu T, Ozaki H, Sawai H. 2006. Systematic characterization of $2^{\prime}$-deoxynucleoside- $5^{\prime}$-triphosphate analogs as substrates for DNA polymerases by polymerase chain reaction and kinetic studies on enzymatic production of modified DNA. Nucleic Acids Res 34: 5383-5394.

Lam WL, Doolittle WF. 1989. Shuttle vectors for the archaebacterium Halobacterium volcanii. Proc Natl Acad Sci 86: 5478-5482.

Lockard RE, Alzner-Deweerd B, Heckman JE, MacGee J, Tabor MW, RajBhandary UL. 1978. Sequence analysis of $5^{\prime}[32 \mathrm{P}]$ labeled mRNA and tRNA using polyacrylamide gel electrophoresis. Nucleic Acids Res 5: 37-56.

Mandal D, Köhrer C, Su D, Russell SP, Krivos K, Castleberry CM, Blum P, Limbach PA, Soll D, RajBhandary UL. 2010. Agmatidine a modified cytidine in the anticodon of archaeal tRNA ${ }^{\text {Ile }}$, base pairs with adenosine but not with guanosine. Proc Natl Acad Sci 107: 2872-2877.
Muramatsu T, Nishikawa K, Nemoto F, Kuchino Y, Nishimura S, Miyazawa T, Yokoyama S. 1988. Codon and amino-acid specificities of a transfer RNA are both converted by a single post-transcriptional modification. Nature 336: 179-181.

Murao K, Saneyoshi M, Harada F, Nishimura S. 1970. Uridin-5-oxy acetic acid: A new minor constituent from $E$. coli valine transfer RNA I. Biochem Biophys Res Commun 38: 657-662.

Murao K, Hasegawa T, Ishikura H. 1976. 5-methoxyuridine: A new minor constituent located in the first position of the anticodon of tRNA $^{\text {Ala }}$, tRNA ${ }^{\text {Thr }}$, and tRNA ${ }^{\text {al }}$ from Bacillus subtilis. Nucleic Acids Res 3: 2851-2860.

Nieuwlandt DT, Daniels CJ. 1990. An expression vector for the archaebacterium Haloferax volcanii. J Bacteriol 172: 7104-7110.

Nirenberg M. 1968. The genetic code. In Nobel lectures, Elsevier, Amsterdam.

Nishimura S. 1979. Chromatographic mobilities of modified nucleotides. In tRNA: Structure, properties, and recognition (ed. Schimmel PR, Söll D, Abelson JN), pp. 551-552. Cold Spring Harbor Laboratory, Cold Spring Harbor, NY.

Phillips G, de Crecy-Lagard V. 2011. Biosynthesis and function of tRNA modifications in Archaea. Curr Opin Microbiol 14: 335-341.

RajBhandary UL. 1980. Recent developments in methods for RNA sequencing using in vitro ${ }^{32} \mathrm{P}$-labeling. Fed Proc 39: 2815-2821.

Ramesh V, RajBhandary UL. 2001. Importance of the anticodon sequence in the aminoacylation of tRNAs by methionyl-tRNA synthetase and by valyl-tRNA synthetase in an Archaebacterium. J Biol Chem 276: 3660-3665.

Randau L, Pearson M, Söll D. 2005. The complete set of tRNA species in Nanoarchaeum equitans. FEBS Lett 579: 2945-2947.

Sakata S, Shibuya S, Machida H, Yoshino H, Hirota K, Senda S, Ikeda K, Mizuno Y. 1980. Synthesis and antiherpesviral activity of 5-C-substituted uracil nucleosides. Nucleic Acids Symp Ser 8: s39-s42.

Sambrook J, Russell DW. 2001. Molecular cloning: A laboratory manual. Cold Spring Harbor Laboratory Press, Cold Spring Harbor, NY.

Senger B, Auxilien S, Englisch U, Cramer F, Fasiolo F. 1997. The modified wobble base inosine in yeast tRNA ${ }^{\text {Ile }}$ is a positive determinant for aminoacylation by isoleucyl-tRNA synthetase. Biochemistry 36: 8269-8275.

Shevack A, Gewitz HS, Hennemann B, Yonath A, Wittmann HG. 1985. Characterization and crystallization of ribosomal particles from Halobacterium marismortui. FEBS Lett 184: 68-71.

Silberklang M, Gillum AM, RajBhandary UL. 1979. Use of in vitro ${ }^{32} \mathrm{P}$ labeling in the sequence analysis of nonradioactive tRNAs. Methods Enzymol 59: 58-109.

Simoncsits A, Brownlee GG, Brown RS, Rubin JR, Guilley H. 1977. New rapid gel sequencing method for RNA. Nature 269: 833-836.

Stanley J, Vassilenko S. 1978. A different approach to RNA sequencing. Nature 274: 87-89.

Suzuki T, Suzuki T. 2007. Chaplet column chromatography: Isolation of a large set of individual RNAs in a single step. Methods Enzymol 425: 231-239.

Taniguchi T, Miyauchi K, Nakane D, Miyata M, Muto A, Nishimura S, Suzuki T. 2013. Decoding system for the AUA codon by tRNA ${ }^{\text {Ile }}$ with the UAU anticodon in Mycoplasma mobile. Nucleic Acids Res 41: 2621-2631.

Varshney U, Lee CP, RajBhandary UL. 1991. Direct analysis of aminoacylation levels of tRNAs in vivo. Application to studying recognition of Escherichia coli initiator tRNA mutants by glutaminyl-tRNA synthetase. J Biol Chem 266: 24712-24718.

Waters E, Hohn MJ, Ahel I, Graham DE, Adams MD, Barnstead M, Beeson KY, Bibbs L, Bolanos R, Keller M, et al. 2003. The genome of Nanoarchaeum equitans: Insights into early archaeal evolution and derived parasitism. Proc Natl Acad Sci 100: 12984-12988.

Yokoyama S, Nishimura S. 1995. Modified nucleosides and codon recognition. In tRNA: Structure, biosynthesis, and function (ed. Söll D, RajBhandary UL), pp. 207-223. American Society for Microbiology, Washington, DC. 

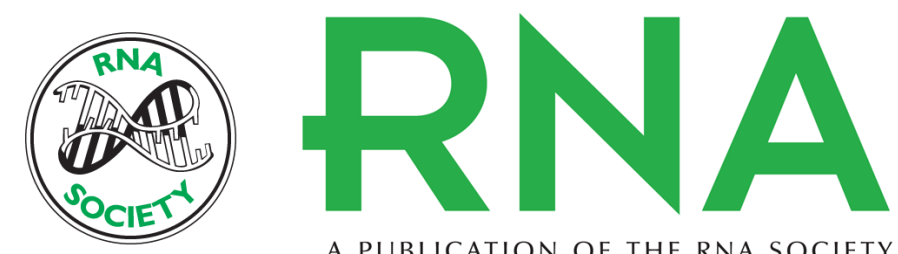

A PUBLICATION OF THE RNA SOCIETY

\section{Identification and codon reading properties of 5-cyanomethyl uridine, a new modified nucleoside found in the anticodon wobble position of mutant haloarchaeal isoleucine tRNAs}

Debabrata Mandal, Caroline Köhrer, Dan Su, et al.

RNA 2014 20: 177-188 originally published online December 16, 2013

Access the most recent version at doi:10.1261/rna.042358.113

Supplemental Material

References

Creative Commons License

Email Alerting Service
http://rnajournal.cshlp.org/content/suppl/2013/12/03/rna.042358.113.DC1

This article cites 38 articles, 9 of which can be accessed free at: http://rnajournal.cshlp.org/content/20/2/177.full.html\#ref-list-1

This article is distributed exclusively by the RNA Society for the first 12 months after the full-issue publication date (see http://rnajournal.cshlp.org/site/misc/terms.xhtml). After 12 months, it is available under a Creative Commons License (Attribution-NonCommercial 3.0 Unported), as described at http://creativecommons.org/licenses/by-nc/3.0/.

Receive free email alerts when new articles cite this article - sign up in the box at the top right corner of the article or click here.

To subscribe to $R N A$ go to:

http://rnajournal.cshlp.org/subscriptions 